\title{
Modeling Temperature Dependency of Oil-Water Relative Permeability in Thermal Enhanced Oil Recovery Processes Using Group Method of Data Handling and Gene Expression Programming
}

\author{
Nait Amar Menad ${ }^{a}$, Zeraibi Noureddine ${ }^{a}$, Abdolhossein Hemmati-Sarapardeh ${ }^{\mathrm{b}}$, Shahaboddin \\ Shamshirband ${ }^{\mathrm{c}, \mathrm{d}, *}$, Amir Mosavi e,f, Kwok-wing Chau ${ }^{\mathrm{g}}$ \\ ${ }^{b}$ Laboratoire Génie Physique des Hydrocarbures, Faculty of Hydrocarbons and Chemistry, University M'hamed Bougara of \\ Boumerdes, Avenue de l'Indépendance, 35000, Boumerdes, Algeria \\ ${ }^{b}$ Department of Petroleum Engineering, Shahid Bahonar University of Kerman, Kerman, Iran \\ ${ }^{c}$ Department for Management of Science and Technology Development, Ton Duc Thang University, Ho Chi Minh City, Vietnam \\ ${ }^{d}$ Faculty of Information Technology, Ton Duc Thang University, Ho Chi Minh City, Vietnam \\ e Institute of Automation, Kando Kalman Faculty of Electrical Engineering, Obuda University, Budapest-1034, \\ Hungary \\ $f$ School of the Built Environment, Oxford Brookes University, Oxford OX30BP, UK \\ ${ }^{g}$ Department of Civil and Environmental Engineering, Hong Kong Polytechnic University, Hong Kong, China
}

\begin{abstract}
In the implementation of thermal enhanced oil recovery (TEOR) techniques, the temperature impact on relative permeability in oil - water systems is of special concern. Hence, developing a fast and reliable tool to model the temperature effect on two-phase oil - water relative permeability is still a major challenge for precise studying and evaluation of TEOR processes. To reach the goal of this work, two promising soft-computing algorithms, namely Group Method of Data Handling (GMDH) and Gene Expression Programming (GEP) were employed to develop reliable, accurate, simple and quick to use paradigms to predict the temperature dependency of relative permeability in oil - water systems $\left(\mathrm{K}_{\mathrm{rw}}\right.$ and $\left.\mathrm{K}_{\mathrm{ro}}\right)$. To do so, a large database encompassing wide-ranging temperatures and fluids/rock parameters, including oil and water viscosities, absolute permeability and water saturation, was considered to establish these correlations. Statistical results and graphical analyses disclosed the high degree of accuracy for the proposed correlations in emulating the experimental results. In addition, GEP based correlations were found to be the most consistent with root mean square error (RMSE) values of 0.0284 and 0.0636 for $\mathrm{K}_{\mathrm{rw}}$ and $\mathrm{K}_{\mathrm{ro}}$, respectively. Lastly, the comparison of the performances of our correlations against those of the preexisting ones indicated the large superiority of the introduced correlations compared to previously published methods. The findings of this study can help for better understanding and studying the temperature dependency of oil - water relative permeability in thermal enhanced oil recovery processes.
\end{abstract}


Keywords - Thermal enhanced oil recovery (TEOR); temperature effect on oil/water relative; group method of data handling (GMDH) and gene expression programming (GEP), machine learning, deep learning

*Corresponding author: Shahaboddin Shamshirband (Shahaboddin.Shamshirband@tdut.edu.vn )

\section{Introduction}

Nowadays, energy demand is expected to rise significantly with the increased prosperity in different sectors of industry and with the higher and continues consumption (Tillerson and others 2008). As fossil source is still the dominant spring of energy, there have been noticeable and significant efforts to promote the standards techniques to improve the outcomes from oil reservoirs (Olayiwola and Dejam 2019). Due to this fact, extraction of oil from unconventional reservoirs and oil with low API gravity has turned into quite important ways to compensate the expected need in the fossil energy (Meyer, Attanasi, and Freeman 2007). The high amount of heavy oils and bitumen over the worldwide raises awareness on this supplementary source of fossil energy although the deficiencies in the characteristics of associated oil such as the high viscosity, low API gravity, and asphaltene content (Saboorian-Jooybari, Dejam, and Chen 2016; Green, Willhite, and others 1998; Prats 1982; Ameli, Alashkar, and Hemmati-Sarapardeh 2018). Therefore, one robust procedure to address such extreme conditions is increasing the temperature by means of steam or hot water injection, to reduce the viscosity which represents the resistance to the flow (Prats 1982). These temperature-based techniques for oil recovery are assembled beneath the umbrella of the so-called Thermal Enhanced Oil Recovery (TEOR).

TOER includes many methods in which the main screening application criterion is based on the viscosity values. Accordingly, we distinguish steam-assisted gravity drainage (SAGD) process that is applied for the recovery of bitumen, steam flooding which is effective for the case of heavy oil extraction and cyclic steam stimulation (CSS) which is appropriate for extraheavy oil (Ameli, Alashkar, and Hemmati-Sarapardeh 2018). It is well known that in such techniques, temperature has strong influence on the porous medium flow; and hence, various 
mechanisms of heat transfer such as convection, conduction, and radiation can take place. In fact, the increase in the in-situ reservoir temperature brings significant effects in interaction of rock-fluid which can impact the behavior of the flow (Akhlaghinia, Torabi, and Chan 2013; Esmaeili et al. 2019a; Ashrafi, Souraki, and Torsaeter 2012). It is worth mentioning that in addition to the presence of heat transfer mechanisms, related-multiphase phenomena such as diffusion and dispersion also make their marks in TOER. As a result, a more complicated multiphase flow in porous media is noticed when implementing TEOR techniques. The commonly applied mathematical approach to describe the flow is these cases is the outgrowth of the Darcy flow equation to multiphase flow (Maini 1998) and thermal-based Darcy flow (Ameli, Alashkar, and Hemmati-Sarapardeh 2018).

Relative permeability is considered a vital factor that is involved in the mathematical models describing the multiphase flow in porous media, in which TEOR processes belong (Nait Amar et al. 2019; Esmaeili et al. 2019b; Maini 1998; Esmaeili et al. 2019a). Relative permeability which is commonly denoted $\mathrm{K}_{\mathrm{r}}$, is recognized as the ratio of effective permeability of a fluid at given saturation to the absolute permeability (Ahmed 2018). Relative permeability data are a must for a large variety of fluid flow calculations related to TEOR. As a matter of fact, modeling and simulation tasks, which are the means to forecast and predict the performances that can be achieved under different scenarios of these techniques cannot be done without the specification of the relative permeability at reservoir conditions. Hence, it is necessary to have accurate and representative values for this parameter to reduce the risks and uncertainties in the simulation results. However, it is needed to add that relative permeability can be affected by various factors and parameters, among which we can cite the absolute permeability, viscosities of water and oil phases and saturation (Honarpour et al. 2006). In addition, the changes made in the fluids and rock proprieties by the temperature upsurge 
influence the relative permeability curves in TEOR (Sinnokrot 1969; Casse, Ramey Jr 1979; Ehrlich 1970; Honarpour et al. 2006; Zhang et al. 2017).

The temperature impact on relative permeability values and the shape of their curves has received considerable attention during last decades (Maini 1998; Zhang et al. 2017; Ashrafi, Souraki, and Torsaeter 2012; Esmaeili et al. 2019a). Although unanimous agreement is not satisfied in this topic, a dominant part of experimental and modeling studies that have been published, have noticed the dependency of relative permeability in oil - water systems (Kro and Krw) on temperature (Schembre et al. 2005; Weinbrandt et al. 1975; Li et al. 2014; Esmaeili et al. 2019b; Esmaeili et al. 2019a). The investigation conducted by (Weinbrandt et al. 1975) confirmed this statement using consolidated Boise sandstone and mineral oil. The studies of (Schembre et al. 2005) and (Li et al. 2014) demonstrated the effect of temperature on the twophase oil-water relative permeability on two distinct cases. In addition, the research performed by (Ehrlich 1970) based on the adsorption resulted in analytical paradigm for the temperature dependency of oil-water relative permeability. Besides, some other models based on IFT as intermediate influencing parameters were developed by (Amaefule and Handy 1982) and (Kumar et al. 1985). To keep the work concise, a deep overview about different studies conducted in the literature to inspect the effect of temperature on relative permeability can be found in our prior published work (Nait Amar et al. 2019) and other relevant publications (Ashrafi, Souraki, and Torsaeter 2012; Esmaeili et al. 2019b; Akhlaghinia, Torabi, and Chan 2013; Esmaeili et al. 2019a; Zhang et al. 2017).

Experimentally, the two-phase oil - water relative permeability in heavy oil cases can be measured by means of three possible techniques: low / high rate displacement tests; and the steady-state co-injection method (Maini 1998). However, the experimental approaches suffer from sensitive drawbacks such as the complexity of lab preparation and realization, the long time needed to accomplish the tests without forgetting the expensive cost. Therefore, in recent 
years, addressing these issues by establishing cheap and simple-to-use methods to gain the impact of temperature on $\mathrm{Kr}$ has triggered a huge amount of scientific inquiry. Zhang et al. (Zhang et al. 2017), Mosavat et al. (Mosavat et al. 2016), Torabi et al. (Torabi, Mosavat, and Zarivnyy 2016), and Bennion et al. (Bennion et al. 2006) are among the well-known predictive correlations that consider the temperature influence on $\mathrm{Kr}$ in oil - water systems. A summary of the aforementioned correlations is given in Table 1. As it is shown in this table, although the form straightforwardness of the prior correlations, they suffer from lack of generalization as their applicability domains are limited to restricted ranges of temperature, rock and fluids parameters. In addition, it should be added that these preexisting correlations have been implemented on the basis of limited databank. In the same context, some other correlations have been established by (Esmaeili et al. 2019c), but these models are not unified with respect to the types of the rock and fluids, and hence, each of them is applicable for specific case, such as consolidated or unconsulated sands interacted with light/heavy.

On the other hand, smart computational techniques have emerged and evolved as powerful and advanced approaches that can resolve highly complex related-modeling topics (Hobold and da Silva 2019; Xi et al. 2018; Shahsavar et al. 2019; Amirian, Dejam, and Chen 2018; Hemmati-Sarapardeh et al. 2018; Hemmati-Sarapardeh et al. 2016; Nait Amar, Zeraibi, and Redouane 2018a; Nait Amar, Zeraibi, and Redouane 2018b; Nait Amar and Zeraibi 2018; Redouane, Zeraibi, and Nait Amar 2018). Among the successful examples of soft computing techniques applications, we can cite production forcasting in thermal enhanced oil recovery (Amirian et al. 2015; Amirian et al. 2018), optimization of enhanced oil recovery techniques (Nait Amar \& Zeraibi 2019), reservoir flood control (Chuntian and Chau 2002), hydrology (Chau 2017; Wu and Chau 2011; Yaseen et al. 2019), and meteorology related topics (Ghorbani et al. 2018; Moazenzadeh et al. 2018). More recently, Esmaeili et al. (Esmaeili et al. 2019b) applied least square support vector machine (LSSVM) to model the dependency of oil - water 
relative permeability on temperature. (Nait Amar et al. 2019) proposed various intelligent paradigms as kinds of trustworthy models to estimate oil - water relative permeability in TEOR by combining radial basis function (RBF) neural network and LSSVM with some natureinspired algorithms. The developed models in the two aforementioned studies showed very satisfactory predictions. The present investigation was done with the aim of implementing explicit, user-friendly and accurate correlations using group method of data handling (GMDH) and gene expression programming (GEP) for predicting the dependency of $\mathrm{Kr}$ in the two - phase oil - water systems on temperature, so that it could be applicable to a wider range of temperature, and fluids and rock proprieties.

In the present work, group method of data handling (GMDH) and gene expression programming (GEP) are applied to establish reliable correlations for estimating temperaturebased oil - water relative permeability through defining five input parameters; namely the saturation of water $\left(S_{w}\right)$, absolute permeability $(\mathrm{K})$, temperature $(\mathrm{T})$, oil and water viscosities $\left(\mu_{o}\right.$ and $\left.\mu_{w}\right)$. To this end, a comprehensive data source of 1223 points gathered from valid available literature and covering an extensive range of rock and fluids parameters and temperature, is utilized to establish the correlations. After developing GEP and GMDH models, they are assessed by means of several statistical criteria and graphical error analyses. Lastly, to testify the reliability of the proposed correlations, these ones are compared with pre-existing correlations that model the dependency of oil - water relative permeability on temperature. There are some important differences between the present study and the previously performed studies in literature: (1) the established paradigms in this study have widespread applicability ranges, and besides, (2) different user-friendly explicit expressions for modeling temperature dependency of Kro and Krw in thermal enhanced oil recovery processes are developed. Fig. 1 recaps the sketch of the problem. 
The next sections of the paper are ordered as follows. Section 2 highlights a detailed description of the databank employed to establish the correlations. Section 3 describes the GMDH and GEP concepts. Results are described and discussed in Section 4. Finally, Section 5 points out the main outcoming results.

\section{Data description}

To develop reliable correlations that can ensure the generalization and accuracy, a comprehensive and a large databank with widespread conditions must be considered. Due to this fact, in this study, 1223 experimental data points were collected from published literature (Poston et al. 1970; Maini and Okazawa 1987; Ashrafi, Souraki, and Torsaeter 2012; Ashrafi, Souraki, and Torsaeter 2014; Torabi, Mosavat, and Zarivnyy 2016; Weinbrandt et al. 1975; Lo and Mungan 1973; Ali A Sinnokrot et al. 1971; Akhlaghinia, Torabi, and Chan 2013). The collected data cove a wide range of temperature and fluid/rock conditions. Among the 1223 points, 648 points describe the oil relative permeability $\left(K_{r o}\right)$ cases, while the remaining 575 correspond to the relative permeability of water $\left(K_{r w}\right)$. The considered inputs to develop the correlations are the following: temperature $(\mathrm{T})$, water saturation $\left(\mathrm{S}_{\mathrm{w}}\right)$, water viscosity $\left(\mu_{w}\right)$, oil viscosity $\left(\mu_{o}\right)$ and the absolute permeability $(\mathrm{K})$. Table 2 reports a full description of the employed databank in this study. It should be mentioned that these data have already been used in our previous paper (Nait Amar et al. 2019).

To establish the correlations using GEP and GMDH, the database was divided randomly into training data covering $80 \%$ of the whole databank, and testing data including the remaining $20 \%$. The training data were used to investigate for the best correlations, while the testing data were exploited to evaluate the behavior of the correlations with blind data.

\section{Models}

\subsection{Group Method of Data Handling (GMDH)}


Group Method of Data Handling (GMDH) known also as polynomial neural network is one of the most promising families of artificial neural networks (ANNs) (Dargahi-Zarandi et al. 2017). Beside the reliability shown by GMDH in modeling complex systems, it ensures the advantage of providing user-friendly polynomial formula to the system being studied. The conception of GMDH technique consists in employing multiple nodes which belong to intermediate layers. The generated value by each GMDH node is calculated based on a quadratic polynomial model that includes the previous neuron. This GMDH version corresponds to the earliest model that was introduced by Ivakhnenko (A.G. Ivakhnenko, G.I. Krotov 1970). As the earliest version of GMDH presented some generalization lacks, a modified version, known also as hybrid version, was proposed as an extensive version that includes more interactions between the nodes and variables; hence, this version ensures more flexibility for modeling more complex systems (Rostami et al. 2019). The GMDH hybrid version follows the below-shown rule:

$$
y_{i}=a+\sum_{i=1}^{d} \sum_{j=1}^{d} \ldots \sum_{k=1}^{d} c_{i j \ldots k} x_{i}^{n} x_{j}^{n} \ldots x_{k}^{n} \quad n=1,2, \ldots, 2^{m}
$$

where $y_{i}, x_{i j \ldots k}$ stand for the inputs and output parameters of the model, respectively; $c_{i j \ldots k}$ denote the polynomial coefficients; $m$ and $d$ mean respectively, the size of layers and the input parameters number.

Afterwards, the full-form mathematical formulation can be done by partial polynomials with predefined orders to combine between the nodes in previous layers; hence, new nodal variables (i.e. $\mathrm{O}_{1}, \mathrm{O}_{2}, \ldots$ ) are created. For the case of two neurons related with a quadratic polynomial model, the following equation is applied:

$$
O_{i}^{G M D H}=a_{0}+a_{1} x_{i}+a_{2} x_{j}+a_{3} x_{i} x_{j}+a_{4} x_{i}^{2}+a_{5} x_{j}^{2}
$$

To adjust the coefficients of the above-shown equation, the least square method (LSM) is applied. Therefore, the following expression is formulated: 


$$
\delta_{j}^{2}=\sum_{i=1}^{N_{t}}\left(y_{i}-O_{i}^{G M D H}\right)^{2} \quad j=1,2, \ldots,\left(\begin{array}{l}
d \\
2
\end{array}\right)
$$

In which $d$ is the variables number and $\mathrm{N}_{\mathrm{t}}$ is the size of the training set.

To solve this problem, this latter if transformed to a matrix form as (Dargahi-Zarandi et al. 2017; Hemmati-Sarapardeh and Mohagheghian 2017):

$$
y=A^{T} X
$$

The LSM generates the solution of Eq. (4) as follows:

$$
A^{T}=y X^{T}\left(X X^{T}\right)^{-1}
$$

where $y=\left\{y_{1}, y_{2}, \ldots, y_{d}\right\}$ and $A=\left\{a_{0}, a_{1}, a_{2}, a_{3}, a_{4}, a_{5}\right\}$, in which $\mathrm{d}$ points out the number for variables.

\subsection{Gene expression programming (GEP)}

Gene expression programming (GEP) is an advanced soft computing method which was introduced by Ferreira (Ferreira 2001). This technique is a part of the family of evolutionary algorithms (EAs) and it applies the evolutionary principles. GEP provides the advantage of generating explicit mathematical expression to the studied systems. From the conception standing point of view, GEP is regarded an improved version of Genetic Programming (GP) introduced by Koza (Koza 1992), as GEP handled the GP issues, such as the limited regression strategies (Ferreira 2001).

As the other evolutionary algorithm, GEP processes the searching for best expression model by employing chromosomes that codify and reflect possible solutions. In addition, another key element which is the Expression Tree (ET) is introduced in GEP. ET is obtained by transforming the chromosomes into real candidates. GEP employs genes that involve terminals and a head containing functions. Each gene has a fixed length list of symbols which represent kinds of operators such as $\{+, \times,-, /, \log , \sqrt{ }\}$ and a terminal set such as 
$\{x, y, z\}$ (Teodorescu and Sherwood 2008). Fig. 2 shows a chromosome having two genes and its mathematical formula.

The GEP searching procedure is summarized in the following steps:

(1) GEP setting parameters: it consists to define the needed key parameters such as the size of the population, the stopping criteria, and the length of genes.

(2) Population initialization: create randomly initial chromosomes (different possible mathematical expression).

(3) Evaluate the chromosomes using a fitness function.

(4) Select the fittest individuals and save them for the next generation.

(5) Apply tournament selection to choose the individuals that will be recombined to generate new offspring. One point and two points recombination are available in GEP.

(6) Mutation operator: mutation plays a principal role in GEP. It changes genomes by modifying an element by another.

(7) Transposition and insertion of sequences somewhere in a chromosome: it consists to activate and jump parts of the genome in the chromosome (Ferreira 2001).

The steps from (3) to (7) are reiterated while the stopping criterion is not satisfied.

\section{Results and discussion}

\subsection{Developing the correlations}

As previously mentioned, after preparing the databank and specifying the training and testing sets for both cases Kro and Krw, the two rigorous techniques namely GEP and GMDH were applied to establish correlations for these two parameters with the following inputs: the saturation of water $\left(S_{w}\right)$, absolute permeability $(\mathrm{K})$, temperature $(\mathrm{T})$, oil and water viscosities 
$\left(\mu_{o}\right.$ and $\left.\mu_{w}\right)$. Therefore, the temperature dependency of oil - water relative permeability correlations are developed with respect to the aforementioned inputs as follows:

$$
\begin{aligned}
& K_{r o}=f\left(S_{w}, T, \mu_{o}, \mu_{w}, K\right) \\
& K_{r w}=f\left(S_{w}, T, \mu_{o}, \mu_{w}, K\right)
\end{aligned}
$$

In both approaches, mean square error (MSE) was defined as the error function to be minimized during the search process for the best correlations. MSE is defined as follows:

$$
M S E=\frac{\sum_{1}^{N}\left(K r_{i_{e x p}}-K r_{i_{p r e}}\right)^{2}}{N}
$$

in which $\mathrm{Kr}$ means the oil or water relative permeability, $\mathrm{N}$ is the number of points and the subscript pre and exp mean the predicted and experimental values, correspondingly.

When implementing GEP technique, its control parameters such as the population size, mutation probability, the included operators, etc. should be tuned to improve the accuracy of the generated correlations. The considered GEP setting parameters in this study are stated in

\section{Table 3.}

A summarized schematic of the $\mathrm{K}_{\mathrm{rw}}$ and $\mathrm{K}_{\mathrm{ro}}$ correlations obtained with GMDH are presented in Figs. 3 and 4, correspondingly. As it is shown in these figures, the $\mathrm{K}_{\mathrm{rw}}$ network encompasses one input layer, one output layer and three intermediate layers; while for the case of $\mathrm{K}_{\mathrm{ro}}$, one input layer, one output layer and two intermediate layers were obtained. The resulted GMDH correlations are expressed as follows:

- $\mathrm{K}_{\mathrm{rw}}$

$$
\begin{aligned}
& K_{r w}=0.023971+0.790913 \times N_{4}-4.492498 \times 10^{-7} \times K-0.00104 \times T-3.950588 \times 10^{-6} \times \\
& K \times N_{4}-0.000433 \times T \times N_{4}+4.465764 \times 10^{-9} \times T \times K+0.610576 \times N_{4}^{2}+2.816213 \times 10^{-11} \times \\
& K^{2}+1.4329 \times 10^{-5} \times T^{2}+5.142623 \times 10^{-9} \times T \times K \times N_{4}+0.00068 \times K \times N_{4}^{2}-2.7281999 \times \\
& 10^{-10} \times K^{2} \times N_{4}+0.002079 \times T \times N_{4}^{2}+2.737294 \times 10^{-13} \times T \times K^{2}-8.539067 \times 10^{-6} \times T^{2} \times N_{4}- \\
& 1.877768 \times 10^{-10} \times T^{2} \times K-0.58709 \times N_{4}^{3}-3.568052 \times 10^{-16} \times K^{3}-4.849053 \times 10^{-8} \times T^{3}
\end{aligned}
$$

- $\mathrm{K}_{\mathrm{ro}}$ 


$$
\begin{aligned}
& K_{\text {ro }}=0.728253-0.072037 \times N_{2}+3.82443 \times 10^{-5} \times K-3.4903857 \times S_{w}-1.549463 \times 10^{-5} \times \\
& K \times N_{2}+0.100212 \times S_{w} \times N_{2}-1.124351 \times 10^{-5} \times S_{w} \times K+0.934668 \times N_{2}^{2}-9.736863 \times 10^{-10} \times \\
& K^{2}+5.4835969 \times S_{w}^{2}-3.342406 \times 10^{-5} \times S_{w} \times N_{2}-1.073647 \times 10^{-5} \times K \times N_{2}^{2}+4.3652039 \times \\
& 10^{-10} \times K^{2} \times N_{2}+2.154452 \times S_{w} \times N_{2}^{2}+6.461956 \times 10^{-10} \times S_{w} \times K^{2}+0.8212563 \times S_{w}^{2} \times N_{2}- \\
& 3.8461259 \times 10^{-5} \times S_{w}^{2} \times K-0.662322 \times N_{2}^{3}+4.315276 \times 10^{-15} \times K^{3}-2.820277 \times S_{w}^{3}
\end{aligned}
$$

The resulted GMDH nodes and genomes included in the above-obtained correlations are reported in Appendix A.

The obtained correlations by GEP are expressed as follows:

- $\mathrm{K}_{\mathrm{rw}}$

$$
K_{r w}=-\left(0.02353 \times S_{w}+0.1717 \times S_{w}^{2}\right) \times K^{0.5} \times \exp \left(-\mu_{o}\right)-0.0007187+A+B+C+D
$$

where A, B, C and D are defined as shown-below:

$$
\begin{aligned}
& A=\frac{30.40 \times S_{w}^{6}}{\exp \left(-\mu_{o}\right)+\ln (K)-1}-\frac{60.6 \times S_{w}^{6}}{1.759 \times\left(S_{w}^{2}+\ln (K)\right)-0.955} \\
& B=-\frac{3.713 \times S_{w}^{4}}{1.126 \times\left(S_{w}^{2}+\mu_{w}^{2}\right)-8.898}-\frac{7.349 \times S_{w}^{4}}{45.04 \times\left(\mu_{o}+\tanh \left(\mu_{o}\right)\right)-362.7} \\
& C=-\frac{2.123 \times 10^{-5} \times S_{w}^{2} \times T^{2}}{2 \times \mu_{o}+\ln (K)-17.43}-\frac{1.011 \times 10^{-3} \times S_{w}^{4} \times \mu_{o}^{2}}{4.612 \times\left(\mu_{o}+\mu_{w}\right)+73.63} \\
& D=-\frac{29.92 \times S_{w} \times \exp \left(-S_{w}^{2}\right) \times \sqrt{\exp \left(-\mu_{o}\right)}}{T}
\end{aligned}
$$

- $\mathrm{K}_{\mathrm{ro}}$

- For $21.10<T \leq 100^{\circ} \mathrm{C}$

$$
\begin{aligned}
& K_{r o}=0.05447\left(\frac{S_{w} \times T \times \mu_{o}}{K}\right)(0.12071 \times T-1)+0.04403\left(\sqrt{\frac{K}{\mu_{w}}}\right)\left(\frac{0.2376}{\sqrt{\mu_{w}}}-1\right)+\mu_{o}\left(0.00619+\frac{17.9}{T-K}\right)+ \\
& A_{1} \times S_{w}-A_{2} \times\left(S_{w} \times T \times \mu_{w}\right)-A_{3} \times\left(\frac{\mu_{w}}{T}\right)+A_{4} \times\left(\frac{K}{S_{w}}\right)-A_{5}+A_{6} \\
& - \text { For } 100<T \leq 200^{\circ} \mathrm{C} \\
& K_{r o}=0.7083 \times S_{w}^{2} \times\left(0.003467 \times T \times \sqrt{\mu_{o}}-S_{w}^{4}\right)+10^{-6} \times\left[7834 \times \mu_{w}^{3}-5.963 \times\left(T^{2}+\sqrt{\mu_{o}}\right)+\right. \\
& \left.A_{1} \times\left(S_{w} \times K\right)+A_{2}\left(\frac{K}{T}\right)-A_{3}\left(\frac{K}{\mu_{w}}\right)+A_{4} \times \mu_{o}^{\frac{3}{2}}-\frac{A_{5}}{\sqrt{S_{w}}}\right]+A_{6} \times \mu_{o}+A_{7}
\end{aligned}
$$


The expressions of the terms appearing in the obtained GEP correlation for Kro are specified in Table 4.

\subsection{Performances evaluation}

Graphical error analyses and statistical criteria and were employed to assess the accuracy of the developed correlations and chose the best representative ones in forecasting the temperature - based $\mathrm{K}_{\mathrm{ro}}$ and $\mathrm{K}_{\mathrm{rw}}$.

The root mean square error (RMSE) and coefficient of determination $\left(\mathrm{R}^{2}\right)$ and are the statistical indexes that were used in this study. These two statistical criteria are defined in Appendix B.

To fine-tune the above-mentioned criteria, broaden the assessment of the established correlations and give visual comparisons, graphical evaluation diagrams such as cross plots, and histograms of error distribution were considered. In the cross plots, the predicted values by the correlations are plotted versus the counterpart experimental values. Existence of large amount of points nearby the line $\mathrm{Y}=\mathrm{X}$ indicated the high accuracy of the model and the excellent degree of correspondence between predictions and real data. In the histograms of error, the distribution of errors is plotted in a bar form and if a normal distribution is noticed nearby zero value, the model is deemed very satisfactory.

Figs. 5 and 6 display cross plots comparing between experimental data and predictions of GEP and GMDH correlations for Kro and Krw, respectively. As it can be obviously seen from these figures, GMDH predictions show large sparse for both Kro and Krw, whereas the predictions of GEP are accumulated nearly enough around the unit slope line. According to this visual survey, it can be said that the GEP correlations are more awe-inspiring as sublime accommodations between their predictions and experimental results are noticed. To excavate the integrity of the established correlations and distinguish the most representative one, Table 
5 and bar plots of Fig. 7 report statistical and graphical error analyses through the considered assessment criteria, namely RMSE and $\mathrm{R}^{2}$, for the established correlations. With accordance to the demonstrated results in Table 5 and Fig. 7, it can be concluded that GEP correlations estimate better $\mathrm{K}_{\mathrm{rw}}$ and $\mathrm{K}_{\mathrm{ro}}$ compared to GMDH correlations. The temperature-based oil - water relative permeability correlations established using GEP exhibit overall RMSE values of 0.0284 and 0.0636 for $\mathrm{K}_{\mathrm{rw}}$ and $\mathrm{K}_{\mathrm{rw}}$, respectively, and correlation coefficients that exceed 0.97 for the both cases. Therefore, the developed GEP correlations were considered for further investigation in the rest of paper.

To depict effectiveness and reliability of the GEP correlations regarded to the generated results, the comparison between predicted relative permeability from the implemented correlations and their counterpart real values versus corresponding indexes of data samples were demonstrated in Fig. 8 for Kro and in Fig. 9 for Krw. As these figures illustrate, the gained results from the GEP correlations are as close as possible to actual values of Krw and Kro during the training and testing phases.

For a better understanding of the GEP correlations integrity in estimating the temperature - based Kro and Krw, Figs. 10 and 11 demonstrate histograms of errors between the actual and estimated values for Kro and Krw, respectively. These figures include error histograms for training and testing phases in the two cases, Kro and Krw. Based on the reported results in these histograms, we can observe that the most frequent error values are nearby zero. In addition, it can be said that the error distributions follow the normal curve in all the subplots. The error distributions reported in Figs. 10 and 11 confirm the high ability of the established correlations in predicting the temperature - based Kro and Krw.

\subsection{Comparison of developed GEP correlations with literature models}

In the present study, the accuracy of the developed GEP correlations was compared to various available correlations in the literature, which include the effect of temperature on Kro 
and Krw. These latter include Bennion et al. (Bennion et al. 2006), Zhang et al. (Zhang et al. 2017), and Mosavat et al. (Mosavat et al. 2016). It should be mentioned that while applying the preexisting correlations to the employed data in this study, only the points that fall within the application ranges were included according to each correlation. To this end, the estimated values using the previously mentioned correlations versus the experimental data are plotted in Fig. 12 for Kro and in Fig. 13 for Krw. Figs. 12 and 13 demonstrate that large scatters in the Kro and Krw data around the unit slop line were generated by Bennion et al. (Bennion et al. 2006) and Mosavat et al. (Mosavat et al. 2016) correlations, while acceptable accumulation around the $\mathrm{X}=\mathrm{Y}$ line was noticed in the case of estimating Krw with the Zhang et al. (Zhang et al. 2017) correlation. This obviously indicates that Bennion et al. (Bennion et al. 2006) and Mosavat et al. (Mosavat et al. 2016), correlations fail in forecasting the correct values of both Kro and Krw, whereas Zhang et al. (Zhang et al. 2017) fails particularly in predicting Kro.

Table 6 and Fig. 14 summarize the performances of the correlations considered in this work along with those of GEP correlations. The comparison results show that the developed GEP correlations lead to the best performances in predicting both Kro and Krw. According to Table 6 and Fig. 14, it is concluded that the developed GEP correlations outperforms largely the preexisting temperature-based oil/water correlations.

\subsection{Validity of the developed GEP correlations in term of water saturation $\left(S_{w}\right)$}

To testify the efficiency of the established GEP correlations in predicting the curves of temperature - based Kro and Krw as function of $S_{\mathrm{w}}$, Fig. 15 illustrates the generated Kro and Krw curves via GEP correlations, and compare with corresponding experimental values from two different samples included in this study. As the subplots (a) and (b) of Fig. 15 depict, a very satisfactory integrity is shown by the GEP correlations to estimate the temperature-based Kro and Krw curves as their emulated results have almost identical behaviors as actual records do. 
The prediction capability of the proposed GEP correlations has once again been certified in Fig. 15.

Finaly, it should be mentioned that the proposed correlation for modeling the temperature dependency of Kro and Krw should be utilized when the data falls within the applicability realm, otherwise its exactness is not ensured as precise results for certain conditions can be generated, and imprecise results for some others. However, as previously stated, these correlations were gained by including widespread databank, and hence, it can be applied for several cases which have input parameters filling in the applicability realm.

\section{Conclusions}

In this study, new explicit, simple-to-use and accurate correlations were proposed to model the dependency of relative permeability in oil - water systems on temperature. Group method of data handling (GMDH) and gene expression programming (GEP) were implemented as promising tools to implement the correlations using a large comprehensive databank. Several assessment criteria were considered to figure out integrity and performance of the new correlations. The main conclusions of the study are summarized as follows:

1. GEP-based correlations were found as the most reliable correlations to predict the temperature dependency of $\mathrm{Kr}$ in oil - water relative systems.

2. The newly implemented GEP correlations for predicting the temperature-based Kro and Krw exhibited very satisfactory performances with overall RMSE values of 0.0284 and 0.0636 for Krw and Kro, respectively.

3. The developed GEP correlations were compared with other well-known preexisting correlations; namely those of Zhang et al. (Zhang et al. 2017), Bennion et al. (Bennion 
et al. 2006) and Mosavat et al. (Mosavat et al. 2016). The integrity of the proposed correlations was testified and found to be substantially superior to all of these models.

4. By performing a trend analysis of the developed GEP correlations in term of water saturation, the gained curves for both Kro and Krw followed the expected forms and logical variations in term of water saturation.

5. The established correlations in this study can be applied under a wide variety of conditions and also can be improved in presence of new additional data.

\section{Nomenclature}

\section{Acronyms}

ANNs artificial neural networks

CSS cyclic steam stimulation

GEP gene expression programming

GMDH group method of data handling

IFT interfacial tension

LSSVM least square support vector machine

MSE mean square error

RBFNN radial basis function neural network

RMSE Root mean squared error

$\mathrm{R}^{2}$ coefficient of determination

SAGD steam-assisted gravity drainage

TEOR thermal enhanced oil recovery

\section{Variables}

$\mathrm{K}$ absolute permeability

$K_{\text {ro }}$ oil relative permeability

$K_{r w}$ water relative permeability

$\mathrm{S}_{\mathrm{w}}$ water saturation

T temperature

$\mu_{w}$ water viscosity

$\mu_{o}$ oil viscosity

\section{Subscripts}

Min minimum

Max maximum 


\section{Appendix A. Obtained GMDH nodes and genomes for Kro and Krw}

The resulted GMDH nodes and genomes are expressed as follows:

- Krw

$$
\begin{aligned}
& N_{4}=-0.102767-1.983942 \times N_{3}+0.005098 \times T-0.141932 \times S_{w}+0.01020 \times T \times N_{3}+ \\
& 6.158718 \times S_{w} \times N_{3}-0.006264 \times S_{w} \times T+3.078813 \times N_{3}^{2}-4.478272 \times 10^{-5} \times T^{2}+0.931513 \times \\
& S_{w}^{2}-0.010119 \times S_{w} \times T \times N_{3}+0.0011847 \times T \times N_{3}^{2}-1.530084 \times 10^{-5} \times T^{2} \times N_{3}+0.031735 \times S_{w} \times \\
& N_{3}^{2}+2.267592 \times 10^{-5} \times S_{w} \times T^{2}-4.639188 \times S_{w}^{2} \times N_{3}+0.003083 \times S_{w}^{2} \times T-1.635732 \times N_{3}^{3}+ \\
& 1.164436 \times 10^{-5} \times T^{3}-0.7844912 \times S_{w}^{3} \\
& N_{3}=0.176662-1.940022 \times N_{2}+1.3582468 \times N_{1}-0.9801913 \times \mu_{w}+183.489858 \times N_{1} \times N_{2}+ \\
& 0.500095 \times N_{2} \times \mu_{w}+4.220132 \times \mu_{w} \times N_{1}-42.4369441 \times N_{2}^{2}-141.8141161 \times N_{1}^{2}+1.637756 \times \\
& \mu_{w}^{2}-235.2853497 \times \mu_{w} \times N_{1} \times N_{2}-635.636686 \times N_{1} \times N_{2}^{2}+545.98779 \times N_{1}^{2} \times N_{2}+79.564658 \times \\
& \mu_{w} \times N_{2}^{2}+153.550115 \times \mu_{w} \times N_{1}^{2}+2.097266 \times \mu_{w}^{2} \times N_{2}-4.2657881 \times \mu_{w}^{2} \times N_{1}+225.747117 \times \\
& N_{2}^{3}-134.334663 \times N_{1}^{3}-0.891422 \times \mu_{w}^{3}
\end{aligned}
$$$$
N_{2}=-0.096002-5.9257567 \times 10^{-6} \times K-0.000564 \times \mu_{o}+1.130989 \times S_{w}+3.481102 \times 10^{-9} \times
$$$$
\mu_{o} \times K-3.823397 \times 10^{-6} \times S_{w} \times K-3.6069041 \times 10^{-6} \times S_{w} \times \mu_{o}+2.674233 \times 10^{-10} \times K^{2}+
$$$$
1.561068 \times 10^{-6} \times \mu_{o}^{2}-2.949632 \times S_{w}^{2}+1.131077 \times 10^{-9} \times \mu_{o} \times K \times S_{w}-4.770877 \times 10^{-14} \times \mu_{o} \times
$$$$
K^{2}+2.038109 \times 10^{-11} \times \mu_{o}^{2} \times K+1.599609 \times 10^{-10} \times S_{w} \times K^{2}-3.171396 \times 10^{-7} \times S_{w} \times \mu_{o}^{2}-
$$$$
1.538897 \times 10^{-5} \times S_{w}^{2} \times K+0.000121 \times S_{w}^{2} \times \mu_{o}-2.397819 \times 10^{-15} \times K^{3}-9.193278 \times 10^{-10} \times
$$$$
\mu_{o}^{3}+2.792131 \times S_{w}^{3}
$$$$
N_{1}=-0.086648-6.263036 \times 10^{-6} \times K+0.943031 \times S_{w}-2.686239 \times 10^{-6} \times S_{w} \times K+2.763862 \times
$$$$
10^{-10} \times K^{2}-2.593159 \times S_{w}^{2}+1.533535 \times 10^{-10} \times S_{w} \times K^{2}-1.5880239 \times 10^{-5} \times S_{w}^{2} \times K-
$$$$
2.461926 \times 10^{-15} \times K^{3}+2.596955 \times S_{w}^{3}
$$

- Kro 
$N_{2}=-10.615467+3.079713 \times N_{1}+37.847865 \times \mu_{w}+0.123872 \times T-10.501635 \times \mu_{w} \times N_{1}-$ $0.038680 \times T \times N_{1}-0.266058 \times T \times \mu_{w}+4.219898 \times N_{1}^{2}-41.718917 \times \mu_{w}^{2}-0.000483 \times T^{2}+$ $0.067595 \times T \times \mu_{w} \times N_{1}-1.5338197 \times \mu_{w} \times N_{1}^{2}+7.0341954 \times \mu_{w}^{2} \times N_{1}-0.0146348 \times T \times N_{1}^{2}+$ $0.0940588 \times T \times \mu_{w}^{2}+0.000135 \times T^{2} \times N_{1}+0.000562 \times T^{2} \times \mu_{w}-1.465284 \times N_{1}^{3}+15.521063 \times$ $\mu_{w}^{3}+5.4498556 \times 10^{-7} \times T^{3}$

$N_{1}=1.000296-9.2675342 \times 10^{-6} \times K-0.000537 \times \mu_{O}+0.091314 \times S_{w}-7.968958 \times 10^{-8} \times \mu_{O} \times$ $K-1.500484 \times 10^{-5} \times S_{w} \times K-0.001163 \times S_{w}+1.466523 \times 10^{-10} \times K^{2}-9.665598 \times 10^{-7} \times \mu_{O}^{2}-$ $3.759212 \times S_{w}^{2}-3.849348 \times 10^{-8} \times S_{w} \times \mu_{O} \times K+1.066838 \times 10^{-12} \times \mu_{O} \times K^{2}+1.416735 \times 10^{-10} \times$ $\mu_{O}^{2} \times K-4.666963 \times 10^{-11} \times S_{w} \times K^{2}+8.735882 \times 10^{-9} \times S_{w} \times \mu_{O}^{2}+2.5344757 \times 10^{-5} \times S_{w}^{2} \times K+$ $0.001674 \times S_{w}^{2} \times \mu_{O}-5.754639 \times 10^{-16} \times K^{3}+9.856402 \times 10^{-10} \times \mu_{O}^{3}+2.665978 \times S_{w}^{3}$

\section{Appendix B. Statistical criteria}

These two assessment criteria are defined as follows:

$$
\begin{gathered}
R^{2}=1-\frac{\sum_{i=1}^{N}\left(K r_{i_{p r e d}}-K r_{i_{\text {exp }}}\right)^{2}}{\sum_{i=1}^{N}\left(K r_{i_{\text {pred }}}-\overline{K r}\right)^{2}} \\
R M S E=\sqrt{\frac{1}{N} \sum_{i=1}^{N}\left(K r_{i_{\text {exp }}}-K r_{i_{\text {pred }}}\right)^{2}}
\end{gathered}
$$

In these equations, $\mathrm{N}$ corresponds to the number of data, $K r_{i}$ and $\overline{K r}$ are the phase (oil / water) relative permeability and their corresponding averages, correspondingly; and the subscripts pred and $\exp$ mean the predicted and experimental values, correspondingly.

\section{References}

A.G. Ivakhnenko, G.I. Krotov, N. Ivakhnenko. 1970. “Theoretical Systems Ecology: Advances and 
Case Studies."

Ahmed, Tarek. 2018. Reservoir Engineering Handbook. Gulf Professional Publishing.

Akhlaghinia, Manoochehr, Farshid Torabi, and Christine W Chan. 2013. "Effect of Temperature on Two-Phase Relative Permeabilities of Heavy Oil, Water, Carbon Dioxide, and Methane Determined by Displacement Technique." Energy \& Fuels 27 (3). ACS Publications: 11851193.

Ali Ghorbani, Mohammad, Reza Kazempour, Kwok-Wing Chau, Shahaboddin Shamshirband, and Pezhman Taherei Ghazvinei. 2018. "Forecasting Pan Evaporation with an Integrated Artificial Neural Network Quantum-Behaved Particle Swarm Optimization Model: A Case Study in Talesh, Northern Iran.” Engineering Applications of Computational Fluid Mechanics 12 (1). Taylor \& Francis: 724-737.

Amaefule, Jude O, Lyman L Handy, and others. 1982. "The Effect of Interfacial Tensions on Relative Oil/Water Permeabilities of Consolidated Porous Media." Society of Petroleum Engineers Journal 22 (03). Society of Petroleum Engineers: 371-381.

Ameli, Forough, Ali Alashkar, and Abdolhossein Hemmati-Sarapardeh. 2018. "Thermal Recovery Processes."

Amirian, Ehsan, Morteza Dejam, and Zhangxin Chen. 2018. "Performance Forecasting for Polymer Flooding in Heavy Oil Reservoirs." Fuel 216. Elsevier: 83-100.

Amirian, Ehsan, Eugene Fedutenko, Chaodong Yang, Zhangxin Chen, and Long Nghiem. 2018. "Artificial Neural Network Modeling and Forecasting of Oil Reservoir Performance." In Applications of Data Management and Analysis, 43-67. Springer.

Amirian, Ehsan, Juliana Y Leung, Stefan Zanon, and Peter Dzurman. 2015. "Integrated Cluster Analysis and Artificial Neural Network Modeling for Steam-Assisted Gravity Drainage Performance Prediction in Heterogeneous Reservoirs." Expert Systems with Applications 42 (2). Elsevier: 723-740.

Ashrafi, Mohammad, Yaser Souraki, and Ole Torsaeter. 2012. "Effect of Temperature on Athabasca Type Heavy Oil--Water Relative Permeability Curves in Glass Bead Packs." Energy and Environment Research 2 (2): 113.

Ashrafi, Mohammad, Yaser Souraki, and Ole Torsaeter. 2014. "Investigating the Temperature Dependency of Oil and Water Relative Permeabilities for Heavy Oil Systems." Transport in Porous Media 105 (3). Springer: 517-537.

Bennion, D B, F B Thomas, B Schulmeister, T Ma, and others. 2006. "A Correlation of the Low and High Temperature Water-Oil Relative Permeability Characteristics of Typical Western Canadian Unconsolidated Bitumen Producing Formations." In Canadian International Petroleum Conference.

Casse, Francis J, Henry J Ramey Jr, and others. 1979. "The Effect of Temperature and Confining Pressure on Single-Phase Flow in Consolidated Rocks (Includes Associated Paper 9087)." Journal of Petroleum Technology 31 (08). Society of Petroleum Engineers: 1-51.

Chau, Kwok-wing. 2017. "Use of Meta-Heuristic Techniques in Rainfall-Runoff Modelling." Multidisciplinary Digital Publishing Institute.

Chuntian, Cheng, and Kwok-Wing Chau. 2002. "Three-Person Multi-Objective Conflict Decision in Reservoir Flood Control.” European Journal of Operational Research 142 (3). Elsevier: 625631.

Dargahi-Zarandi, Atefeh, Abdolhossein Hemmati-Sarapardeh, Sassan Hajirezaie, Bahram Dabir, and Saeid Atashrouz. 2017. "Modeling Gas/Vapor Viscosity of Hydrocarbon Fluids Using a Hybrid GMDH-Type Neural Network System.” Journal of Molecular Liquids 236. Elsevier: 162-171.

Ehrlich, Robert, and others. 1970. "The Effect of Temperature on Water-Oil Imbibition Relative Permeability." In SPE Eastern Regional Meeting.

Esmaeili, Sajjad, Hemanta Sarma, Thomas Harding, and Brij Maini. 2019a. "Review of the Effect of Temperature on Oil-Water Relative Permeability in Porous Rocks of Oil Reservoirs." Fuel 237. Elsevier: 91-116.

Esmaeili, Sajjad, Hemanta Sarma, Thomas Harding, and Brij Maini. 2019b. "A Data-Driven Model for Predicting the Effect of Temperature on Oil-Water Relative Permeability." Fuel 236. Elsevier: 264-277.

Esmaeili, Sajjad, Hemanta Sarma, Thomas Harding, and Brij Maini. 2019c. "Correlations for Effect of 
Temperature on Oil/Water Relative Permeability in Clastic Reservoirs." Fuel 246. Elsevier: 93103.

Ferreira, Cândida. 2001. "Algorithm for Solving Gene Expression Programming: A New Adaptive Problems." Complex Systems 13 (2): 87-129.

Green, Don W, G Paul Willhite, and others. 1998. Enhanced Oil Recovery. Vol. 6. Henry L. Doherty Memorial Fund of AIME, Society of Petroleum Engineers Richardson, TX.

Hemmati-Sarapardeh, Abdolhossein, Forough Ameli, Amir Varamesh, Shahaboddin Shamshirband, Amir H Mohammadi, and Bahram Dabir. 2018. "Toward Generalized Models for Estimating Molecular Weights and Acentric Factors of Pure Chemical Compounds.” International Journal of Hydrogen Energy 43 (5). Elsevier: 2699-2717.

Hemmati-Sarapardeh, Abdolhossein, Mohammad-Hossein Ghazanfari, Shahab Ayatollahi, and Mohsen Masihi. 2016. "Accurate Determination of the CO2-Crude Oil Minimum Miscibility Pressure of Pure and Impure CO2 Streams: A Robust Modelling Approach.” The Canadian Journal of Chemical Engineering 94 (2). Wiley Online Library: 253-261.

Hemmati-Sarapardeh, Abdolhossein, and Erfan Mohagheghian. 2017. "Modeling Interfacial Tension and Minimum Miscibility Pressure in Paraffin-Nitrogen Systems: Application to Gas Injection Processes." Fuel 205. Elsevier: 80-89.

Hobold, Gustavo M, and Alexandre K da Silva. 2019. "Automatic Detection of the Onset of Film Boiling Using Convolutional Neural Networks and Bayesian Statistics." International Journal of Heat and Mass Transfer 134. Elsevier: 262-270.

Honarpour, M M, N R Nagarajan, K Sampath, and others. 2006. "Rock/Fluid Characterization and Their Integration-Implications on Reservoir Management." Journal of Petroleum Technology 58 (09). Society of Petroleum Engineers: 120-130.

Koza, John R. 1992. Genetic Programming II, Automatic Discovery of Reusable Subprograms. MIT Press, Cambridge, MA.

Kumar, S, S J Torabzadeh, L L Handy, and others. 1985. "Relative Permeability Functions for Highand Low-Tension Systems at Elevated Temperatures." In SPE California Regional Meeting.

Li, Bin, Wan fen $\mathrm{Pu}$, Ke xing Li, Hu Jia, Ke Yu Wang, and Zai guang Yang. 2014. "The Characteristics and Impacts Factors of Relative Permeability Curves in High Temperature and Low-Permeability Limestone Reservoirs." Advanced Materials Research.

Lo, Hing Y, N Mungan, and others. 1973. "Effect of Temperature on Water-Oil Relative Permeabilities in Oil-Wet and Water-Wet Systems." In Fall Meeting of the Society of Petroleum Engineers of AIME.

Maini, B, and others. 1998. "Is It Futile to Measure Relative Permeability for Heavy Oil Reservoirs?" Journal of Canadian Petroleum Technology 37 (04). Petroleum Society of Canada.

Maini, BRIJ B, T Okazawa, and others. 1987. "Effects of Temperature on Heavy Oil-Water Relative Permeability of Sand." Journal of Canadian Petroleum Technology 26 (03). Petroleum Society of Canada.

Menad, Nait Amar, and Zeraibi Noureddine. 2019. "An Efficient Methodology for Multi-Objective Optimization of Water Alternating CO2 EOR Process." Journal of the Taiwan Institute of Chemical Engineers 99. Elsevier: 154-165.

Meyer, Richard F, Emil D Attanasi, and Philip A Freeman. 2007. Heavy Oil and Natural Bitumen Resources in Geological Basins of the World.

Moazenzadeh, Roozbeh, Babak Mohammadi, Shahaboddin Shamshirband, and Kwok-wing Chau. 2018. "Coupling a Firefly Algorithm with Support Vector Regression to Predict Evaporation in Northern Iran.” Engineering Applications of Computational Fluid Mechanics 12 (1). Taylor \& Francis: 584-597.

Mosavat, Nader, Adel Mohsenzadeh, Yahya Al-Wahaibi, and others. 2016. "Estimating Oil/Water Relative Permeability at SAGD Steam Chamber Edge.” In SPE Heavy Oil Conference and Exhibition.

Nait Amar, Menad, Zeraibi Noureddine, Abdolhossein Hemmati-Sarapardeh, and Shahaboddin Shamshirband. 2019. "Modeling Temperature-Based Oil-Water Relative Permeability by Integrating Advanced Intelligent Models with Grey Wolf Optimization: Application to Thermal Enhanced Oil Recovery Processes." Fuel 242 (April). Elsevier: 649-663. doi:10.1016/J.FUEL.2019.01.047. 
Nait Amar, Menad, Nourddine Zeraibi, and Kheireddine Redouane. 2018a. "Optimization of WAG Process Using Dynamic Proxy, Genetic Algorithm and Ant Colony Optimization." Arabian Journal for Science and Engineering 43 (11). Springer: 6399-6412.

Nait Amar, Menad, Nourddine Zeraibi, and Kheireddine Redouane. 2018b. "Bottom Hole Pressure Estimation Using Hybridization Neural Networks and Grey Wolves Optimization." Petroleum 4 (4). Elsevier: 419-429.

Nait Amar, Menad, and Noureddine Zeraibi. 2018. "Application of Hybrid Support Vector Regression Artificial Bee Colony for Prediction of MMP in CO2-EOR Process." Petroleum. Elsevier.

Olayiwola, Saheed Olawale, and Morteza Dejam. 2019. "A Comprehensive Review on Interaction of Nanoparticles with Low Salinity Water and Surfactant for Enhanced Oil Recovery in Sandstone and Carbonate Reservoirs." Fuel 241. Elsevier: 1045-1057.

Poston, S W, S Ysrael, AKMS Hossain, E F Montgomery III, and others. 1970. "The Effect of Temperature on Irreducible Water Saturation and Relative Permeability of Unconsolidated Sands." Society of Petroleum Engineers Journal 10 (02). Society of Petroleum Engineers: 171180.

Prats, Michael. 1982. "Thermal Recovery.” SPE of AIME, New York, NY.

Redouane, Kheireddine, Nourddine Zeraibi, and Menad Nait Amar. 2018. "Automated Optimization of Well Placement via Adaptive Space-Filling Surrogate Modelling and Evolutionary Algorithm.” In Abu Dhabi International Petroleum Exhibition \& Conference.

Rostami, Alireza, Abdolhossein Hemmati-Sarapardeh, Abdorreza Karkevandi-Talkhooncheh, Maen M Husein, Shahaboddin Shamshirband, and Timon Rabczuk. 2019. "Modeling Heat Capacity of Ionic Liquids Using Group Method of Data Handling: A Hybrid and Structure-Based Approach." International Journal of Heat and Mass Transfer 129. Elsevier: 7-17.

Saboorian-Jooybari, Hadi, Morteza Dejam, and Zhangxin Chen. 2016. "Heavy Oil Polymer Flooding from Laboratory Core Floods to Pilot Tests and Field Applications: Half-Century Studies." Journal of Petroleum Science and Engineering 142. Elsevier: 85-100.

Schembre, Josephina Maria, Guo-qing Tang, Anthony Robert Kovscek, and others. 2005. "Effect of Temperature on Relative Permeability for Heavy-Oil Diatomite Reservoirs." In SPE Western Regional Meeting.

Shahsavar, Amin, Shoaib Khanmohammadi, Arash Karimipour, and Marjan Goodarzi. 2019. "A Novel Comprehensive Experimental Study Concerned Synthesizes and Prepare Liquid ParaffinFe3O4 Mixture to Develop Models for Both Thermal Conductivity \& Viscosity: A New Approach of GMDH Type of Neural Network." International Journal of Heat and Mass Transfer 131. Elsevier: 432-441.

Sinnokrot, A A. 1969. "The Effect of Temperature on Capillary Pressure Curves of Limestone and Sandstones [Ph. D. Dissertation]." Stanford University.

Sinnokrot, Ali A, Hi J Ramey Jr, S S Marsden Jr, and others. 1971. "Effect of Temperature Level upon Capillary Pressure Curves." Society of Petroleum Engineers Journal 11 (01). Society of Petroleum Engineers: 13-22.

Teodorescu, Liliana, and Daniel Sherwood. 2008. "High Energy Physics Event Selection with Gene Expression Programming." Computer Physics Communications 178 (6). Elsevier: 409-419.

Tillerson, Rex W, and others. 2008. "Meeting Global Energy Supply and Demand Challenges." In 19th World Petroleum Congress.

Torabi, Farshid, Nader Mosavat, and Ostap Zarivnyy. 2016. "Predicting Heavy Oil/Water Relative Permeability Using Modified Corey-Based Correlations.” Fuel 163. Elsevier: 196-204.

Weinbrandt, R M, H J Ramey Jr, F J Casse, and others. 1975. "The Effect of Temperature on Relative and Absolute Permeability of Sandstones." Society of Petroleum Engineers Journal 15 (05). Society of Petroleum Engineers: 376-384.

Wu, C L, and K W Chau. 2011. "Rainfall--Runoff Modeling Using Artificial Neural Network Coupled with Singular Spectrum Analysis." Journal of Hydrology 399 (3-4). Elsevier: 394-409.

Xi, Lei, Jianmin Gao, Liang Xu, Zhen Zhao, and Yunlong Li. 2018. "Study on Heat Transfer Performance of Steam-Cooled Ribbed Channel Using Neural Networks and Genetic Algorithms." International Journal of Heat and Mass Transfer 127. Elsevier: 1110-1123.

Yaseen, Zaher Mundher, Sadeq Oleiwi Sulaiman, Ravinesh C Deo, and Kwok-Wing Chau. 2019. "An Enhanced Extreme Learning Machine Model for River Flow Forecasting: State-of-the-Art, 
Practical Applications in Water Resource Engineering Area and Future Research Direction.” Journal of Hydrology 569. Elsevier:387-408.

Zhang, Lie-hui, Jing Tong, Yu Xiong, and Yu-long Zhao. 2017. "Effect of Temperature on the Oil-Water Relative Permeability for Sandstone Reservoirs." International Journal of Heat and Mass Transfer 105. Elsevier: 535-548. 
Table 1. Summary of the important correlations for temperature-based oil/water relative permeability prediction. Bennion et al. (Bennion et al. 2006), Mosavat et al. (Mosavat et al.

2016), Torabi et al. (Torabi, Mosavat, and Zarivnyy 2016) and Zhang et al. (Zhang et al. 2017) are

\begin{tabular}{|c|c|c|c|}
\hline Model & \multicolumn{2}{|l|}{ Correlations } & \multirow{5}{*}{$\begin{array}{l}\text { Note } \\
\text { - On the basis of : } \\
\text { - McMurray sand } \\
\text { - Unsteady state / steady } \\
\text { state } \\
\text { - Heavy oil } \\
\text { - Darcy law / history } \\
\text { match } \\
\text { - Restrictions: } \\
\text { - } 0.11<S_{w i}<0.43 \\
\text { - } 0.12<S_{o r}<0.72 \\
\text { - } 8000<\mu_{o}<10^{6} c P\end{array}$} \\
\hline \multirow{4}{*}{$\begin{array}{l}\text { (Bennion et } \\
\text { al. 2006) }\end{array}$} & \multirow{2}{*}{$60^{\circ} \mathrm{C}<T<100^{\circ} \mathrm{C}$} & $K_{r w}=0.021\left(1-\frac{0.6-S_{w}}{0.45}\right)^{5}$ & \\
\hline & & $K_{r o}=\left(\frac{0.6-S_{w}}{0.45}\right)^{2.2}$ & \\
\hline & \multirow{2}{*}{$150^{\circ} \mathrm{C}<T<275^{\circ} \mathrm{C}$} & $055\left(1-\frac{0.85-S_{w}}{0.7}\right)^{2.5}$ & \\
\hline & & $K_{r o}=\left(\frac{0.85-S_{w}}{0.7}\right)^{3}$ & \\
\hline \multirow{2}{*}{$\begin{array}{l}\text { (Torabi, } \\
\text { Mosavat, and } \\
\text { Zarivnyy } \\
\text { 2016) }\end{array}$} & \multicolumn{2}{|c|}{$\begin{array}{r}K_{r w}=0.0466\left(0.0588 \frac{P_{\text {exp }}}{P_{s t d}}\right)^{-1.28676} \times e^{0.34443\left(2-\frac{q_{\text {exp }}}{q_{s t d}}\right)} \\
\times\left(0.0025 \frac{\mu_{o}}{\mu_{s t d}}\right)^{-0.34267}\left(\frac{S_{w}-S_{w i}}{1-S_{w i}}\right)^{2}\end{array}$} & \multirow{2}{*}{$\begin{array}{l}\text { - On the basis of: } \\
\text { - Berea sandstone } \\
\text { - Unsteady } \\
\text { approach } \\
\text { - Heavy oil and light oil } \\
\text { - JBN method } \\
\text { - Restrictions: } \\
-0.092<S_{w i}<0.138 \\
-0.463<S_{o r}<0.539 \\
-27<T<45^{\circ} \mathrm{C} \\
\bullet 24.3<\mu_{o}<400.2 \mathrm{cP}\end{array}$} \\
\hline & \multicolumn{2}{|c|}{$K_{r o}=\left(0.0588 \frac{P_{\text {exp }}}{P_{s t d}}\right)^{-0.0291} \times e^{-0.01254\left(2-\frac{q_{\text {exp }}}{q_{s t d}}\right)} \times\left(1-\frac{S_{w}-S_{w i}}{1-S_{w i}}\right)^{2}$} & \\
\hline \multirow[b]{2}{*}{$\begin{array}{l}\text { (Mosavat et } \\
\text { al. 2016) }\end{array}$} & $K_{r w}=\left(\frac{S_{w}-S_{w i}}{1-S_{w i}}\right)^{a}$ & $\begin{array}{l}a \\
=1.32+0.00123\left(\frac{\mu_{o}}{\mu_{w}}\right)\end{array}$ & $\begin{array}{l}\text { - On the basis of : } \\
\text { - Ottawa silica sand }\end{array}$ \\
\hline & $K_{r o}=\left(1-\left(\frac{S_{w}-S_{w i}}{1-S_{w i}}\right)^{b}\right)\left(1-\frac{S_{w}-S_{w i}}{1-S_{w i}}\right)^{c}$ & $\begin{array}{l}-7.47 \times 10^{-7}\left(\frac{\mu_{o}}{\mu_{w}}\right)^{2} \\
b \\
=102+0.000298\left(\frac{\mu_{o}}{\mu_{w}}\right) \\
-1.38 \times 10^{-7}\left(\frac{\mu_{o}}{\mu_{w}}\right)^{2} \\
c \\
=2.22+0.00318\left(\frac{\mu_{o}}{\mu_{w}}\right) \\
-1.22 \times 10^{-6}\left(\frac{\mu_{o}}{\mu_{w}}\right)^{2}\end{array}$ & $\begin{array}{l}\text { - Unsteady state } \\
\text { approach } \\
\text { - Heavy oil } \\
\text { - History match } \\
\quad-\quad \text { Restrictions: } \\
-0.05<S_{w i}<0.105 \\
\cdot 0.2<S_{o r}<0.413 \\
\cdot 23<T<100^{\circ} \mathrm{C} \\
\cdot 19.5<\mu_{o}<1860 \mathrm{cP}\end{array}$ \\
\hline \multirow[b]{2}{*}{$\begin{array}{l}\text { (Zhang et al. } \\
\text { 2017) }\end{array}$} & $\begin{array}{l}K_{r w} \\
=K_{r w}^{0-50 c}\left(e_{1}+e_{2} T+\frac{e_{3}}{T}\right. \\
\left.+\frac{e_{4}}{T^{2}}\right)\left(\frac{S_{w}-S_{w i}}{1-S_{w i}-S_{o r}}\right)^{a_{3} T+a_{4}}\end{array}$ & \multirow{2}{*}{$\begin{array}{l}e_{1}=20.14 \\
e_{2}=-0.053 \\
e_{3}=-1638.84 \\
e_{4}=40763.24 \\
a_{1}=0.0244 \\
a_{2}=3.8848 \\
a_{3}=-0.0001 \\
a_{4}=0.5099 \\
b_{1}=0.0025 \\
b_{2}=0.1941 \\
c_{1}=-0.1121 \\
c_{2}=0.6711\end{array}$} & \multirow{2}{*}{$\begin{array}{l}\text { - On the basis of : } \\
\text { - Tight sand stone } \\
\text { - Unsteady state } \\
\text { approach } \\
\text { - Light oil } \\
\text { - Combination of JBN } \\
\text { and Corey correlation } \\
\text { - Restrictions: } \\
-0.234<S_{w i}<0.482 \\
-0.153<S_{o r}<0.324 \\
-25<T<100{ }^{\circ} \mathrm{C} \\
-4<\mu_{o}<48 \mathrm{cP}\end{array}$} \\
\hline & $\begin{array}{l}K_{\text {ro }} \\
=\left(\frac{1-S_{w}-c_{1} \ln (T)-c_{2}}{1-b_{1} T-b_{2}-c_{1} \ln (T)-c_{2}}\right)^{a_{1} T+a_{2}}\end{array}$ & & \\
\hline
\end{tabular}


Table 2. Statistical description of the input/output data.

\begin{tabular}{|c|c|c|c|c|c|c|}
\hline & & & Max & Min & Mean & SD \\
\hline \multirow{6}{*}{$\begin{array}{l}\text { Oil Relative } \\
\text { Permeability }\end{array}$} & \multirow{5}{*}{ Input } & Absolute permeability (mD) & 95000 & 147 & 21778.9 & 34047.5 \\
\hline & & Temperature $\left({ }^{\circ} \mathrm{C}\right)$ & 200 & 21.10 & 97.75 & 47.31 \\
\hline & & $\mathrm{S}_{\mathrm{w}}$ & 1 & 0.052 & 0.4623 & 0.2010 \\
\hline & & Water viscosity $(\mathrm{cP})$ & 1.10 & 0.136 & 0.42 & 0.29 \\
\hline & & Oil viscosity $(\mathrm{cP})$ & 1190 & 0.419 & 88.93 & 224.38 \\
\hline & Output & $\mathrm{K}_{\mathrm{ro}}$ & 1 & 0 & 0.3634 & 0.3118 \\
\hline \multirow{6}{*}{$\begin{array}{l}\text { Water Relative } \\
\text { Permeability }\end{array}$} & \multirow{5}{*}{ Input } & Absolute permeability $(\mathrm{mD})$ & 95000 & 147 & 23443.39 & 35241 \\
\hline & & Temperature $\left({ }^{\circ} \mathrm{C}\right)$ & 200 & 21.10 & 99.56 & 45.66 \\
\hline & & $\mathrm{S}_{\mathrm{w}}$ & 1 & 0.052 & 0.533 & 0.219 \\
\hline & & Water viscosity (cP) & 1.10 & 0.136 & 0.40 & 0.27 \\
\hline & & Oil viscosity $(\mathrm{cP})$ & 1190 & 0.7 & 88.39 & 223.19 \\
\hline & Output & $\mathrm{K}_{\mathrm{rw}}$ & 1 & 0 & 0.1096 & 0.2029 \\
\hline
\end{tabular}


Table 3. GEP setting parameters used in the study

\begin{tabular}{|l|l|}
\hline Parameters & Value/setting \\
\hline The number of head size & $8-15$ \\
\hline Chromosome & 150 \\
\hline Gene & $8-12$ \\
\hline Population & $300-500$ \\
\hline Mutation rate & 0.25 \\
\hline Inversion rate & 0.1 \\
\hline Operators used & $\begin{array}{l}+,-, \times, /, \text { EXP, } X^{2}, \text { INV, TANH, } \\
\text { LOG , SQRT }\end{array}$ \\
\hline
\end{tabular}


Table 4. Expressions of the terms appearing in Kro GEP correlations

\begin{tabular}{|c|c|c|}
\hline & $21.10<T \leq 100^{\circ} \mathrm{C}$ & $100<T \leq 200^{\circ} \mathrm{C}$ \\
\hline $\mathrm{A}_{1}$ & $0.5492 \times \mu_{w}+3.596 \times S_{w}-\frac{10^{-5} \times T^{2}}{1.3 \times \mu_{o}-10.67562}$ & $5.8-6.343 \times S_{w} \times \sqrt{\mu_{o}}$ \\
\hline $\mathrm{A}_{2}$ & $0.06567+0.1093 \times \tanh \left(\mu_{w}\right)-0.001972 \times S_{w} \times T \times \mu_{w}+\left(\frac{S_{w}}{K}\right) \times(0.467 \times T+3.869)$ & $7422 \times S_{w}-4659 \times \tanh \left(S_{w}\right)-5.8 \times T$ \\
\hline $\mathrm{A}_{3}$ & $0.4542+\mu_{w}(0.001875 \times K+0.007486)+\frac{0.0003327 \times K}{\mu_{w}}$ & $11.01+\frac{1.809}{\mu_{w}}(T-1)$ \\
\hline $\mathrm{A}_{4}$ & $\frac{1.355 \times 10^{-5}}{T \times \mu_{w}^{2}}-\frac{6.954 \times 10^{-6}}{\sqrt{\mu_{o}}}$ & $68.06+6.343 \times S_{w}^{2}$ \\
\hline $\mathrm{A}_{7}$ & & $\begin{aligned} \frac{0.03168+0.009715 \times}{\tanh \left(\mu_{w}\right)} & \\
& -4.208 \\
& \times \tanh \left(\tanh \left(S_{w}\right)\right) \\
& +0.6253 \times \ln \left(S_{w}+\mu_{w}\right)+2.722 \times \sqrt{\mu_{w}} \\
& -1.437 \times \mu_{o}^{\frac{1}{4}}+2.702\end{aligned}$ \\
\hline
\end{tabular}


Table 5. Statistical indexes of the established correlations

\begin{tabular}{|c|c|c|c|c|c|c|c|}
\hline & & Trainin & & Testing & & All & \\
\hline \multirow{3}{*}{$\mathrm{K}_{\mathrm{rw}}$} & & RMSE & $\mathrm{R}^{2}$ & RMSE & $\mathrm{R}^{2}$ & RMSE & $\mathrm{R}^{2}$ \\
\hline & GMDH & 0.0468 & 0.9711 & 0.0408 & 0.9846 & 0.0456 & 0.9738 \\
\hline & GEP & 0.0278 & 0.9899 & 0.0305 & 0.9918 & 0.0284 & 0.9903 \\
\hline \multirow{2}{*}{$\mathrm{K}_{\mathrm{ro}}$} & GMDH & 0.1206 & 0.9221 & 0.1296 & 0.9104 & 0.1224 & 0.9197 \\
\hline & GEP & 0.0610 & 0.9809 & 0.0740 & 0.9737 & 0.0636 & 0.9794 \\
\hline
\end{tabular}


Table 6. Statistical parameters of various models for temperature-based oil-water relative permeability.

\begin{tabular}{|c|c|c|c|}
\hline & & RMSE & $\mathrm{R}^{2}$ \\
\hline \multirow{4}{*}{$\mathrm{K}_{\mathrm{ro}}$} & Mosavat et al. & 0.2982 & 0.8257 \\
\cline { 2 - 4 } & Zhang et al. & 0.1879 & 0.8326 \\
\cline { 2 - 4 } & Bennion et al. & 0.2665 & 0.6240 \\
\cline { 2 - 4 } & GEP & 0.0636 & 0.9794 \\
\hline \multirow{4}{*}{$\mathrm{K}_{\mathrm{rw}}$} & Mosavat et al. & 0.3105 & 0.7687 \\
\cline { 2 - 4 } & Zhang et al. & 0.0451 & 0.8923 \\
\cline { 2 - 4 } & Bennion et al. & 0.2425 & 0.2347 \\
\cline { 2 - 4 } & GEP & 0.0284 & 0.9903 \\
\hline
\end{tabular}




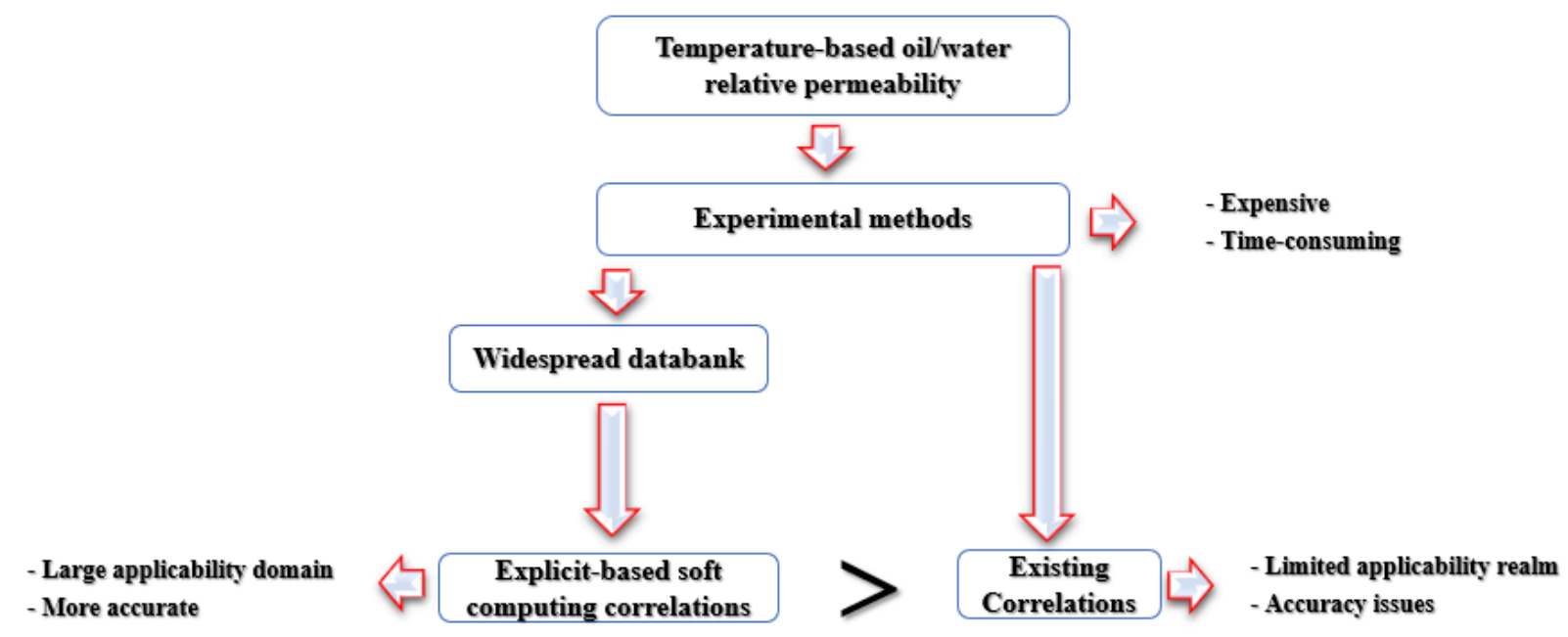

Fig. 1. General sketch of the problem 


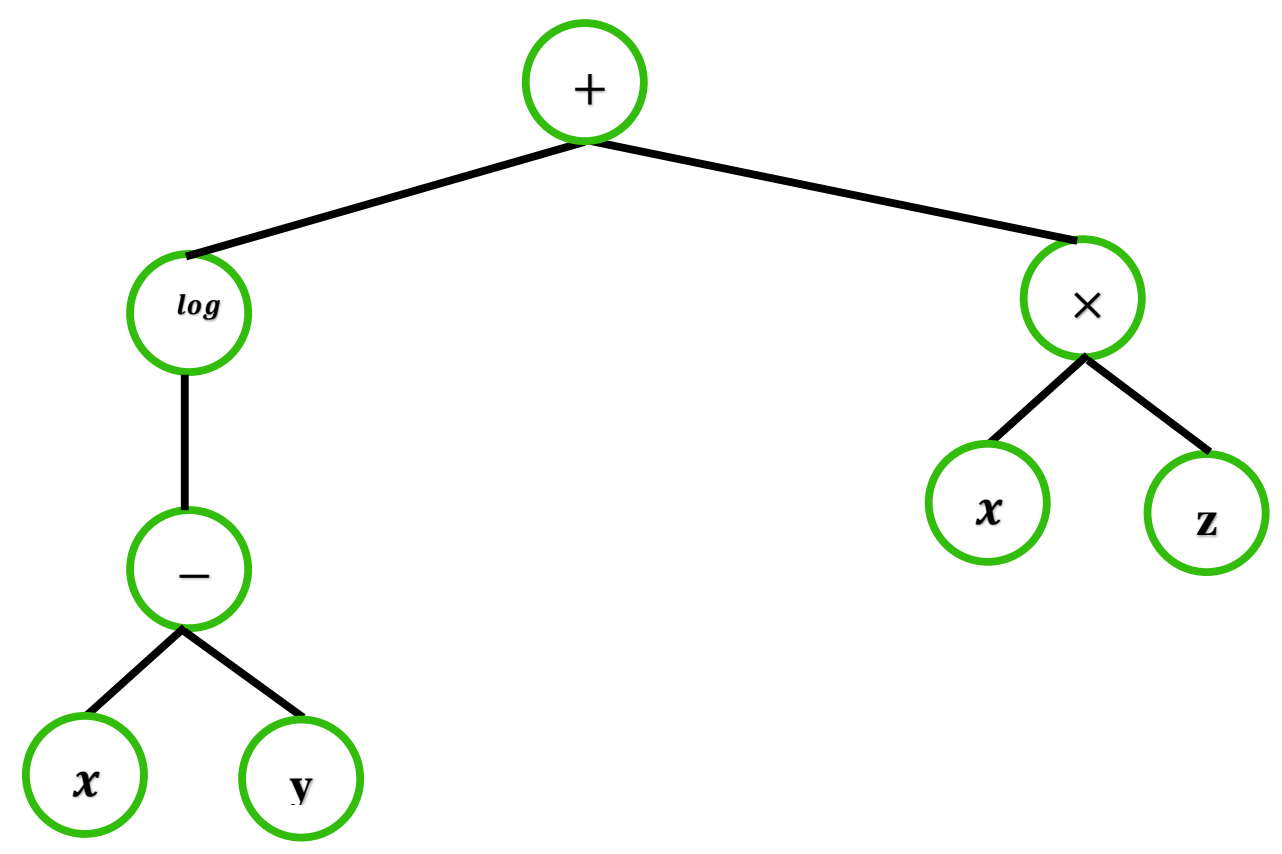

Mathematical expression: $\log (x-y)+x \times z$

Fig. 2. An example of two-gene chromosome and its mathematical expression 


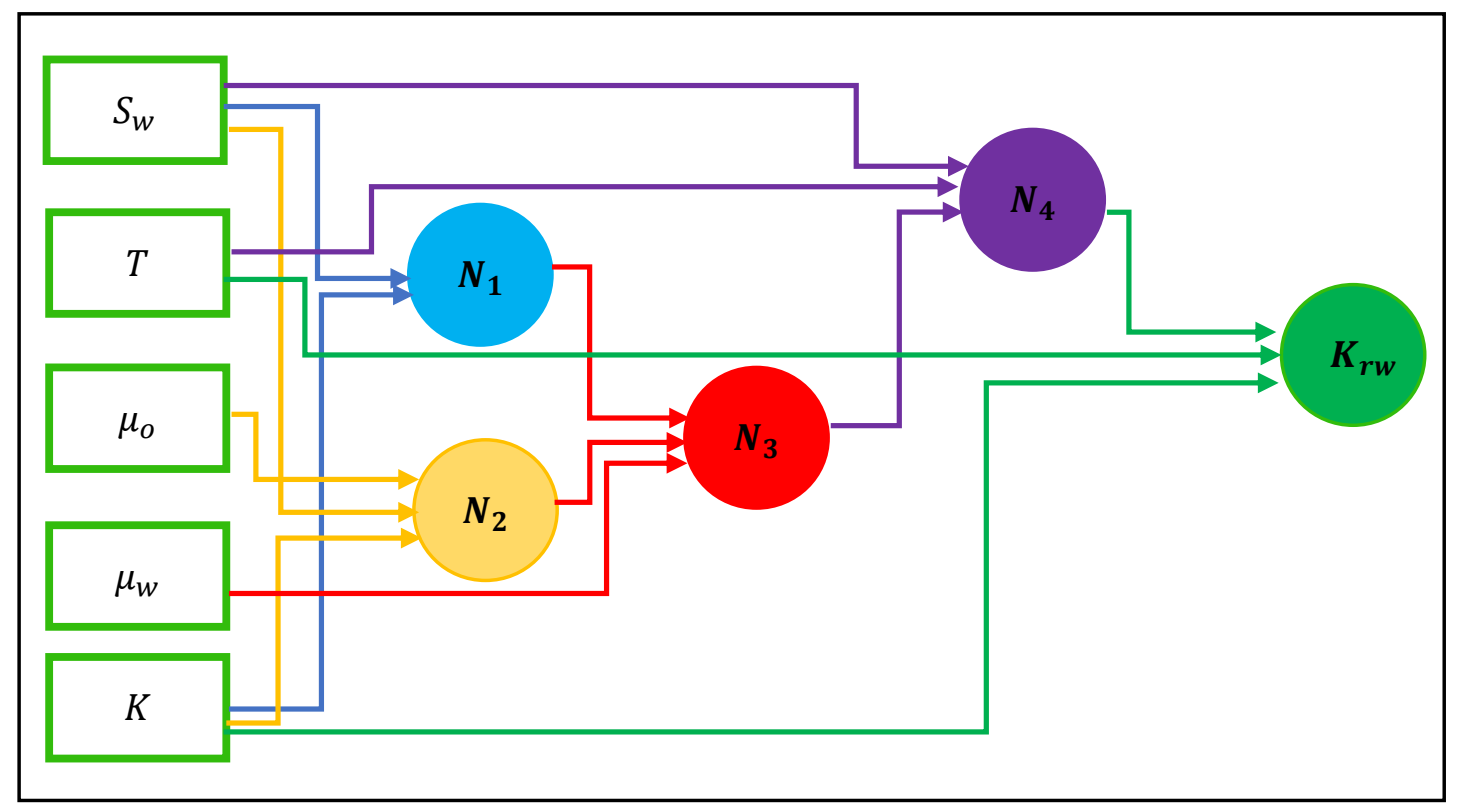

Fig. 3. A schematic structure of the proposed GMDH for predicting Krw 


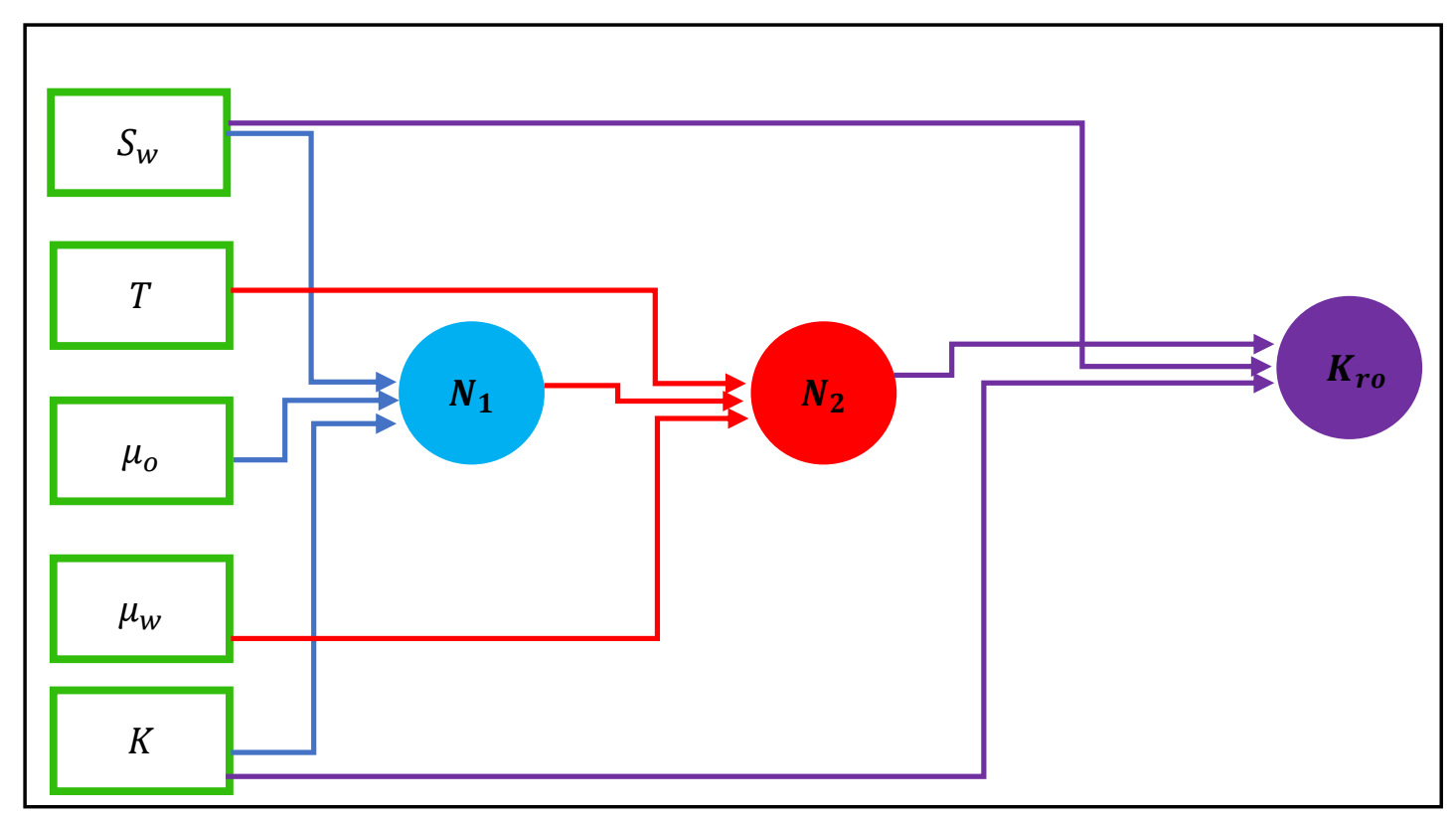

Fig. 4. A schematic structure of the proposed GMDH for predicting Kro 

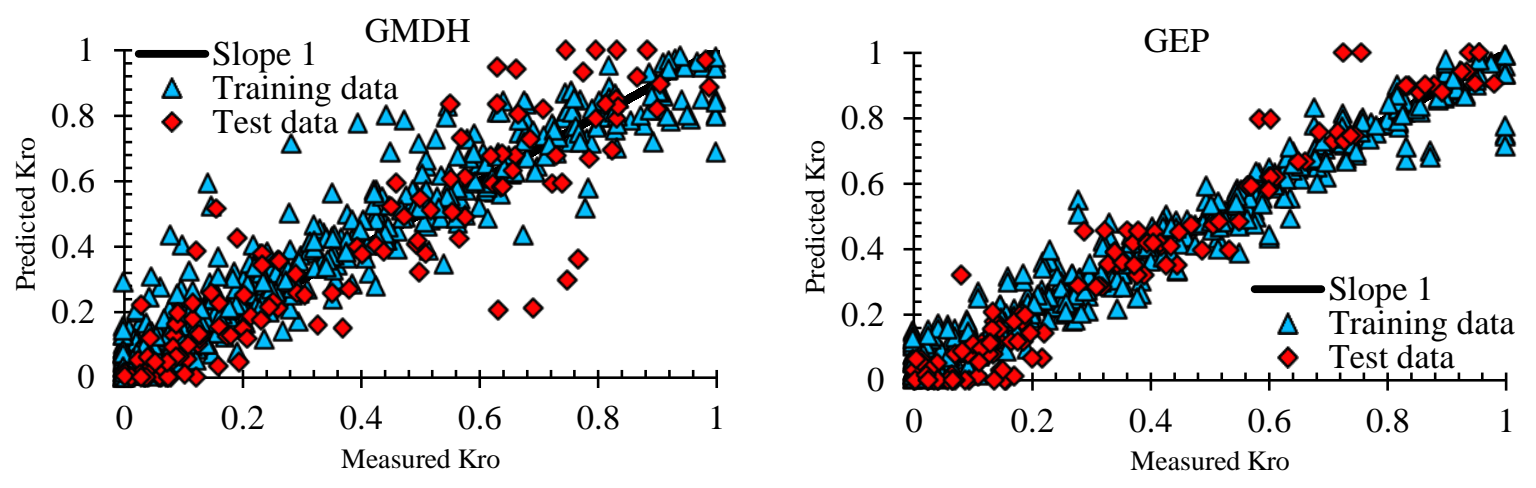

Fig. 5. Cross plots of the established GMDH and GEP correlations (Kro) 

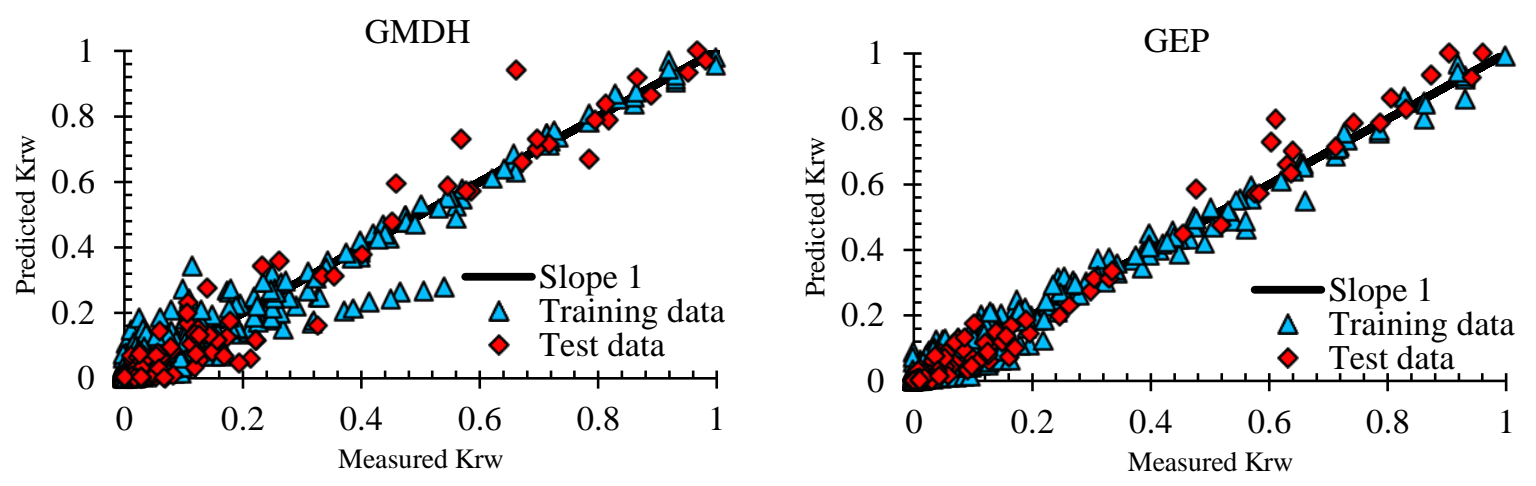

Fig. 6. Cross plots of the established GMDH and GEP correlations (Krw) 
(a)

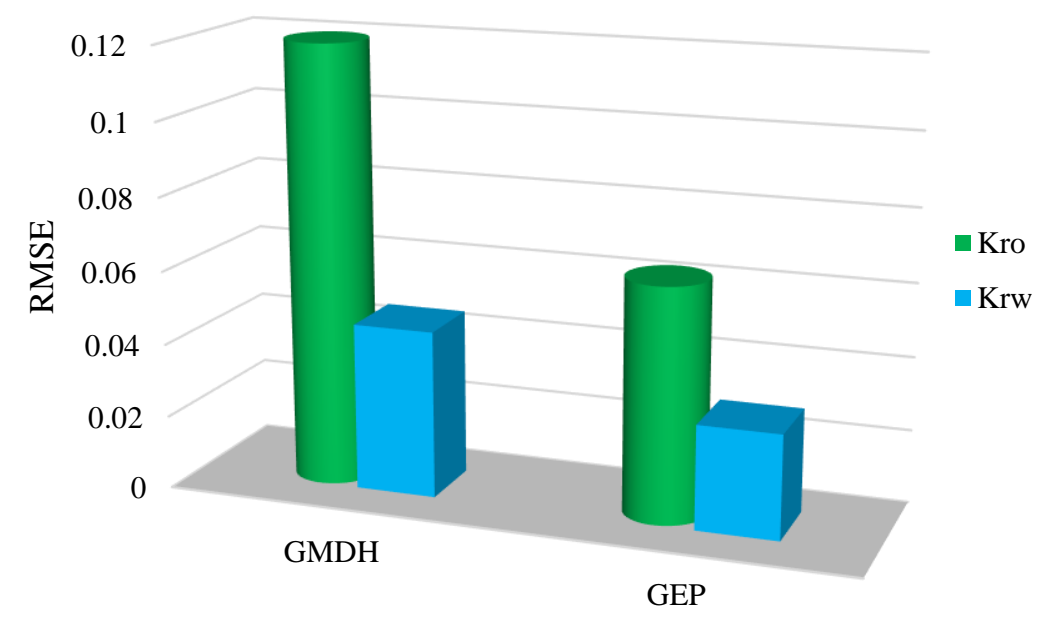

(b)

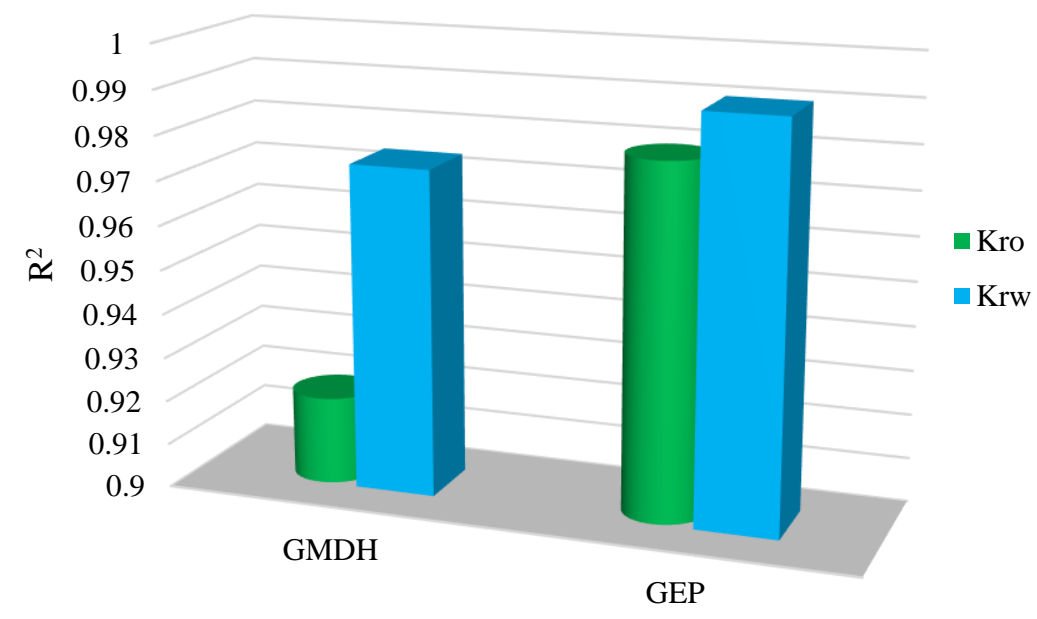

Fig. 7. Comparison between the established correlations: (a) RMSE and (b) $R^{2}$ 


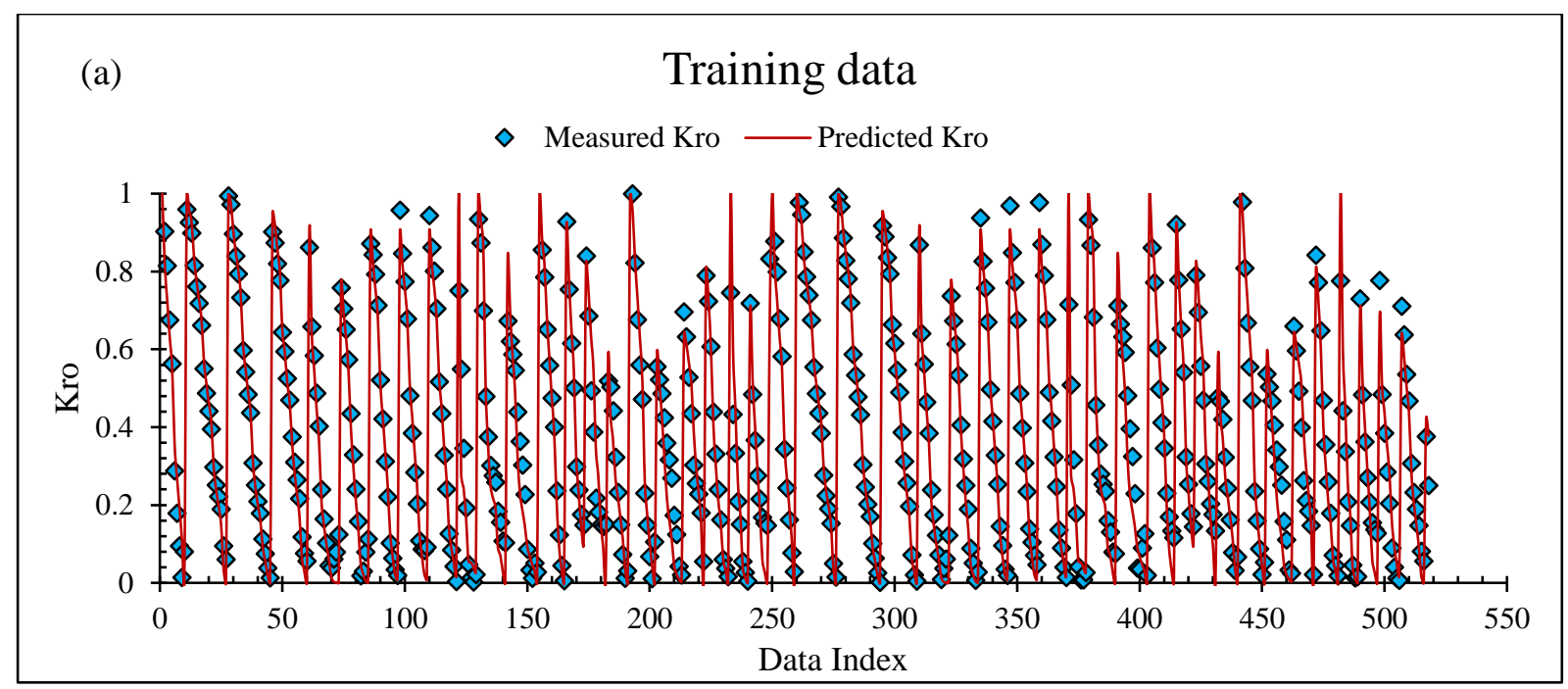

(b)

\section{Tesing data}

$\diamond \quad$ Measured Kro $\quad \longrightarrow$ Predicted Kro

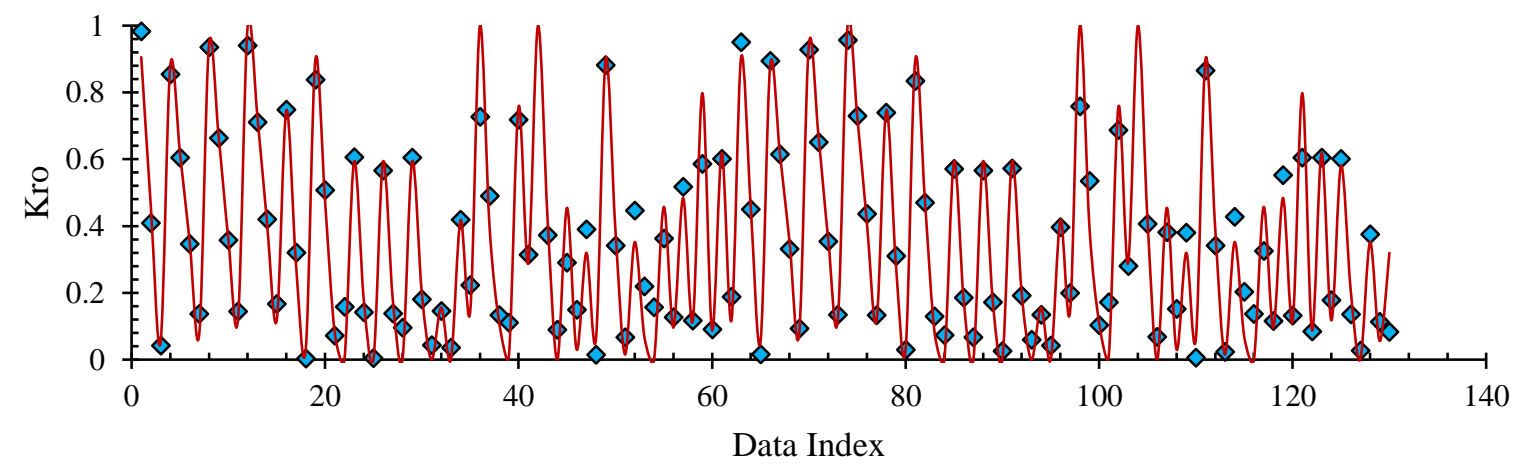

Fig. 8. The comparison between the predicted Kro values by the GEP model and the Kro real values: (a) training data and (b) testing data. 


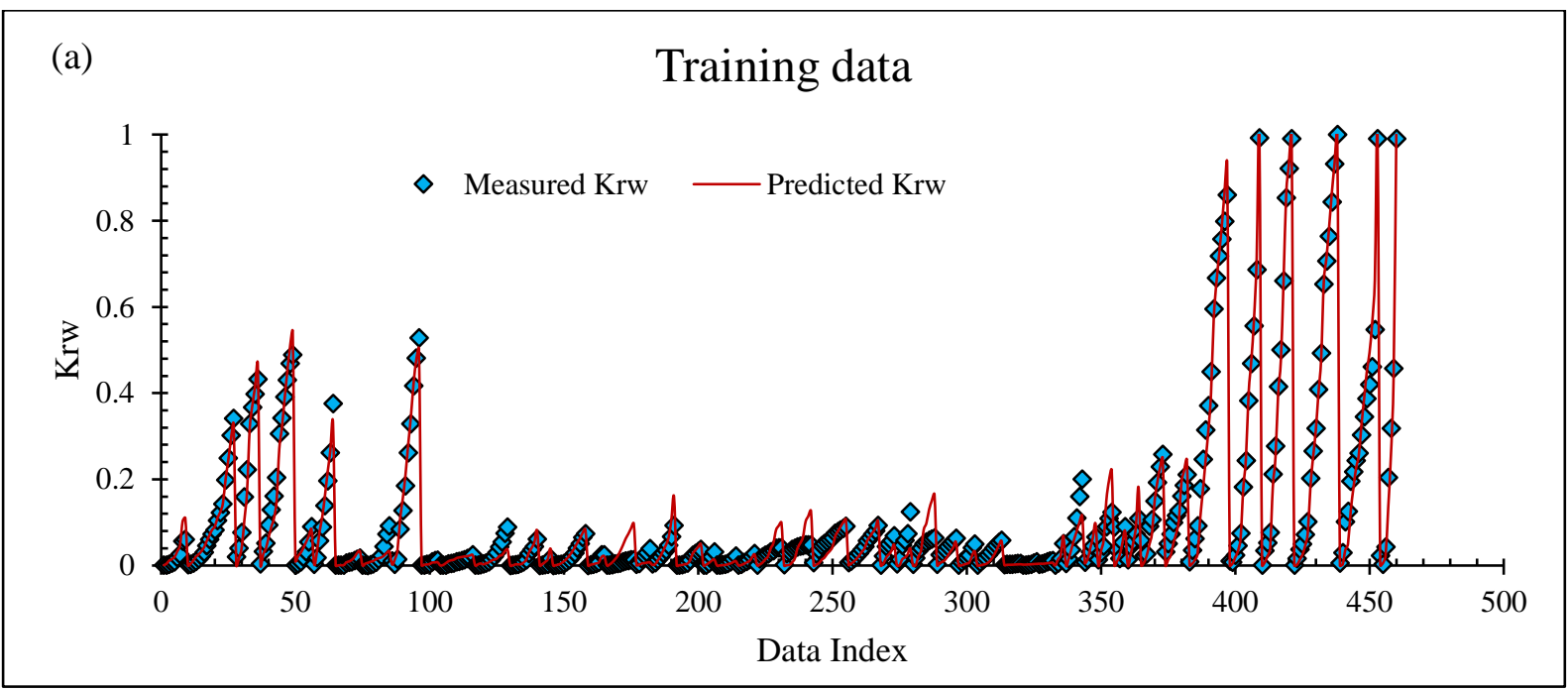

(b)

Testing data

$\diamond \quad$ Measured Krw — Predicted Krw

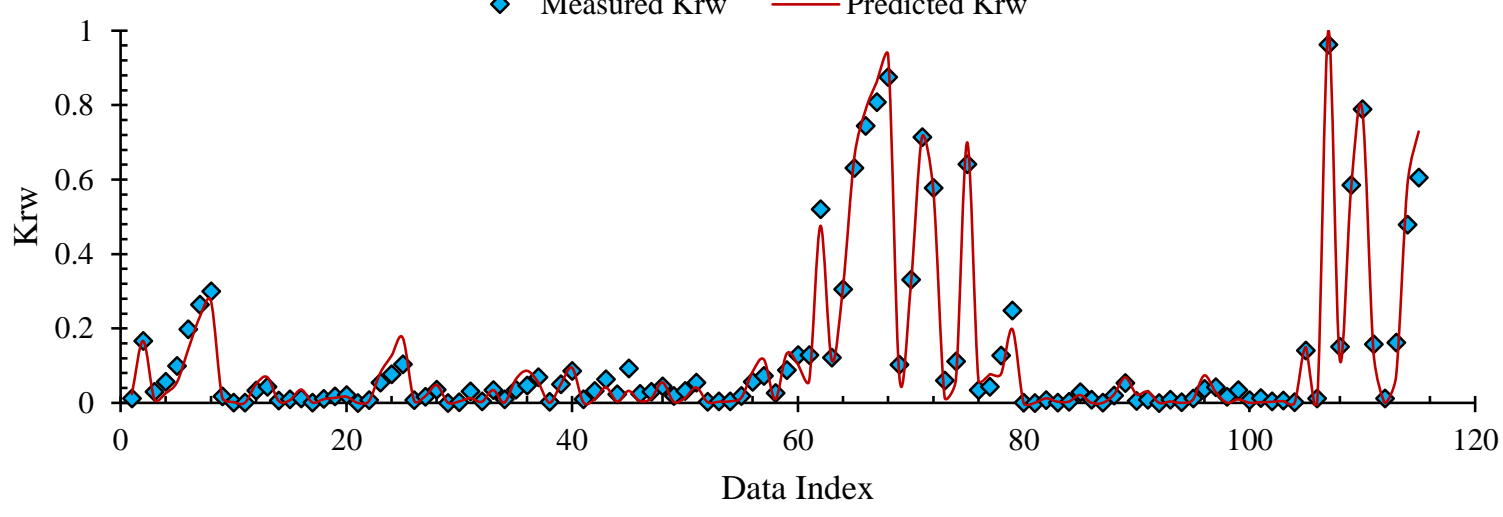

Fig. 9. The comparison between the predicted Krw values by the GEP model and the Krw real values: (a) training data and (b) testing data. 

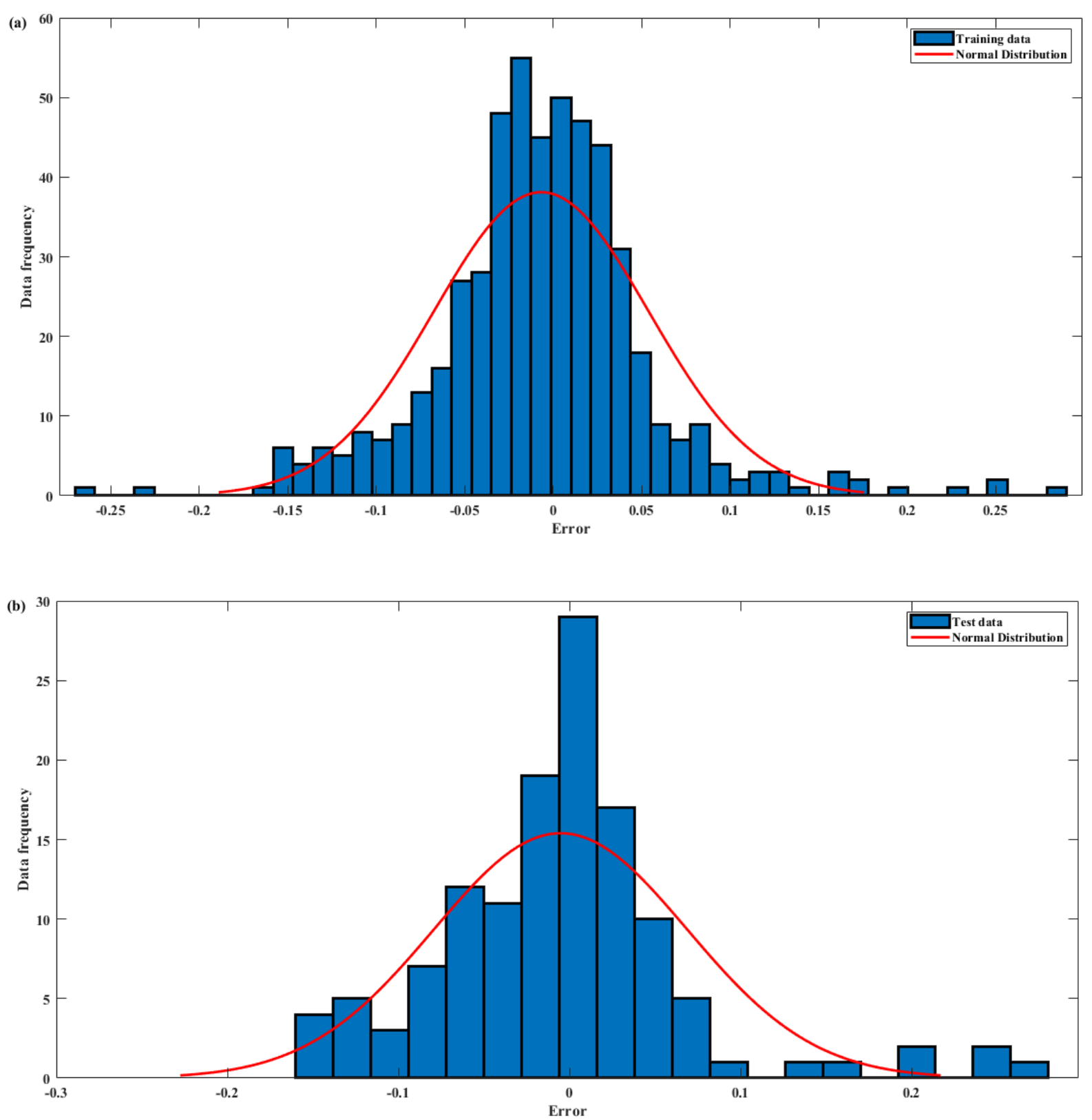

Fig. 10. Histogram plot for the datasets applied in establishing GEP correlation for Kro: (a) train and (b) test. 

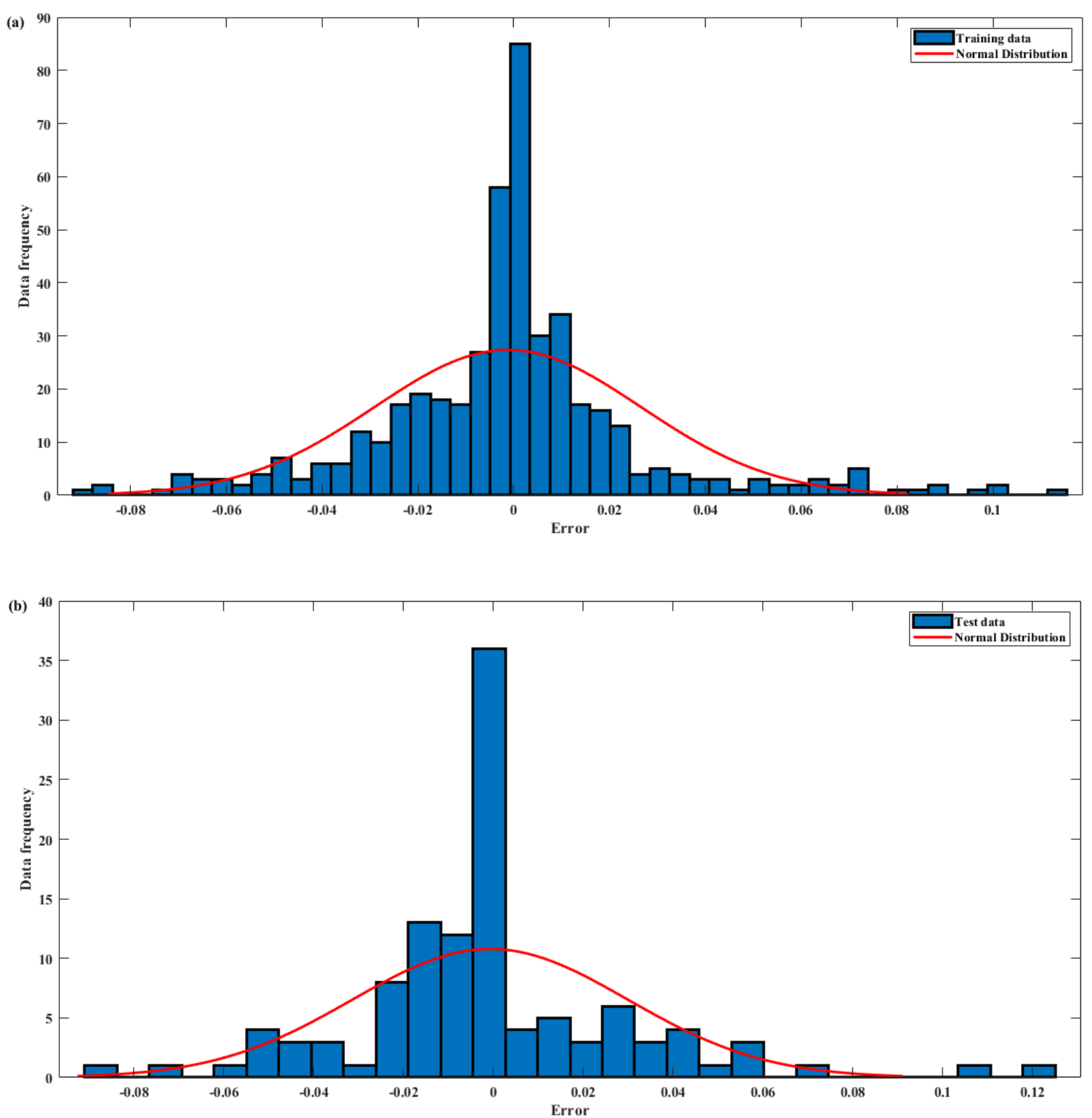

Fig. 11. Histogram plot for the datasets applied in establishing GEP correlation for Krw: (a) train and (b) test. 

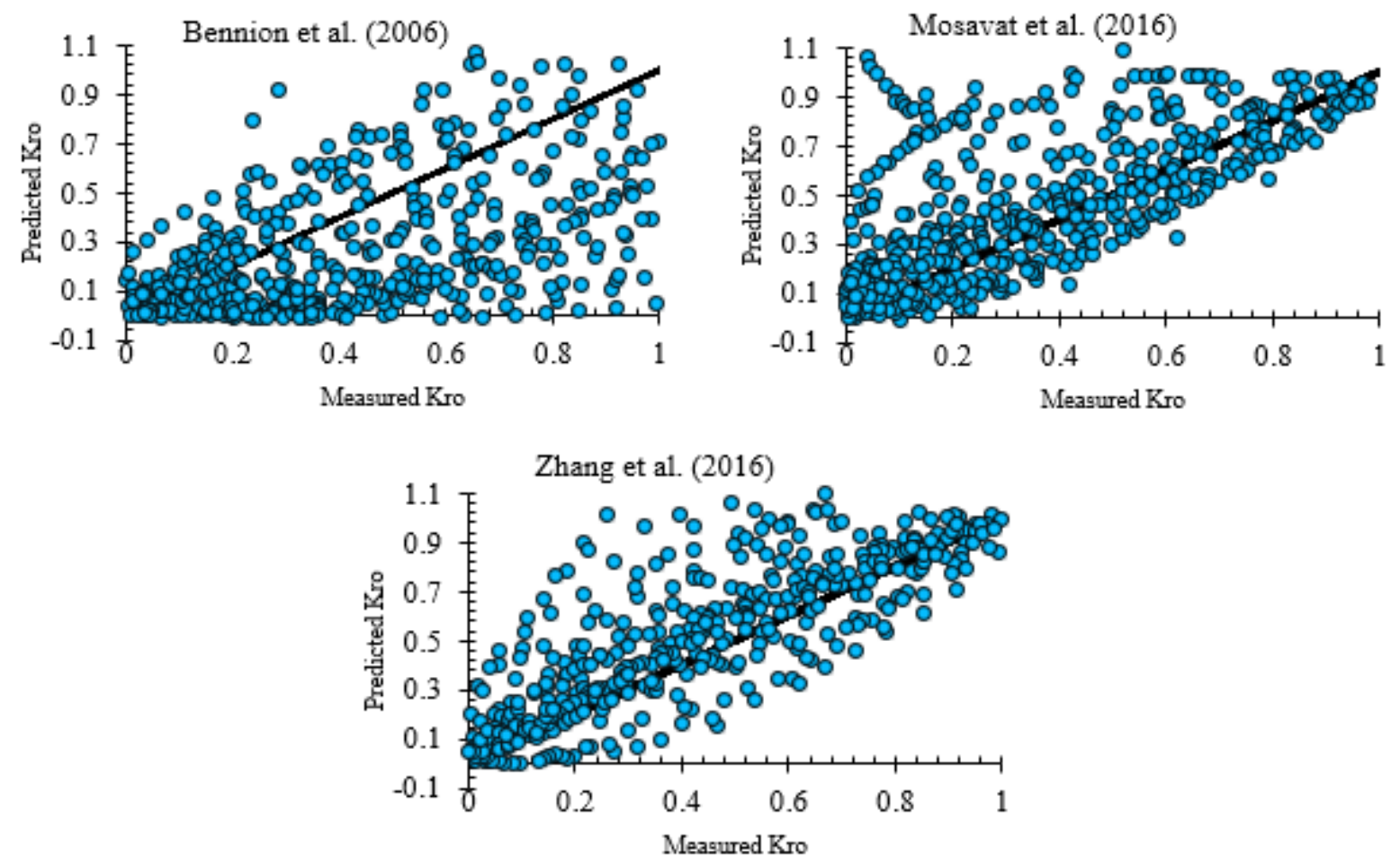

Fig. 12. Comparison of experimental and predicted temperature-based oil relative permeability by Bennion et al., Mosavat et al. and Zhang et al. 

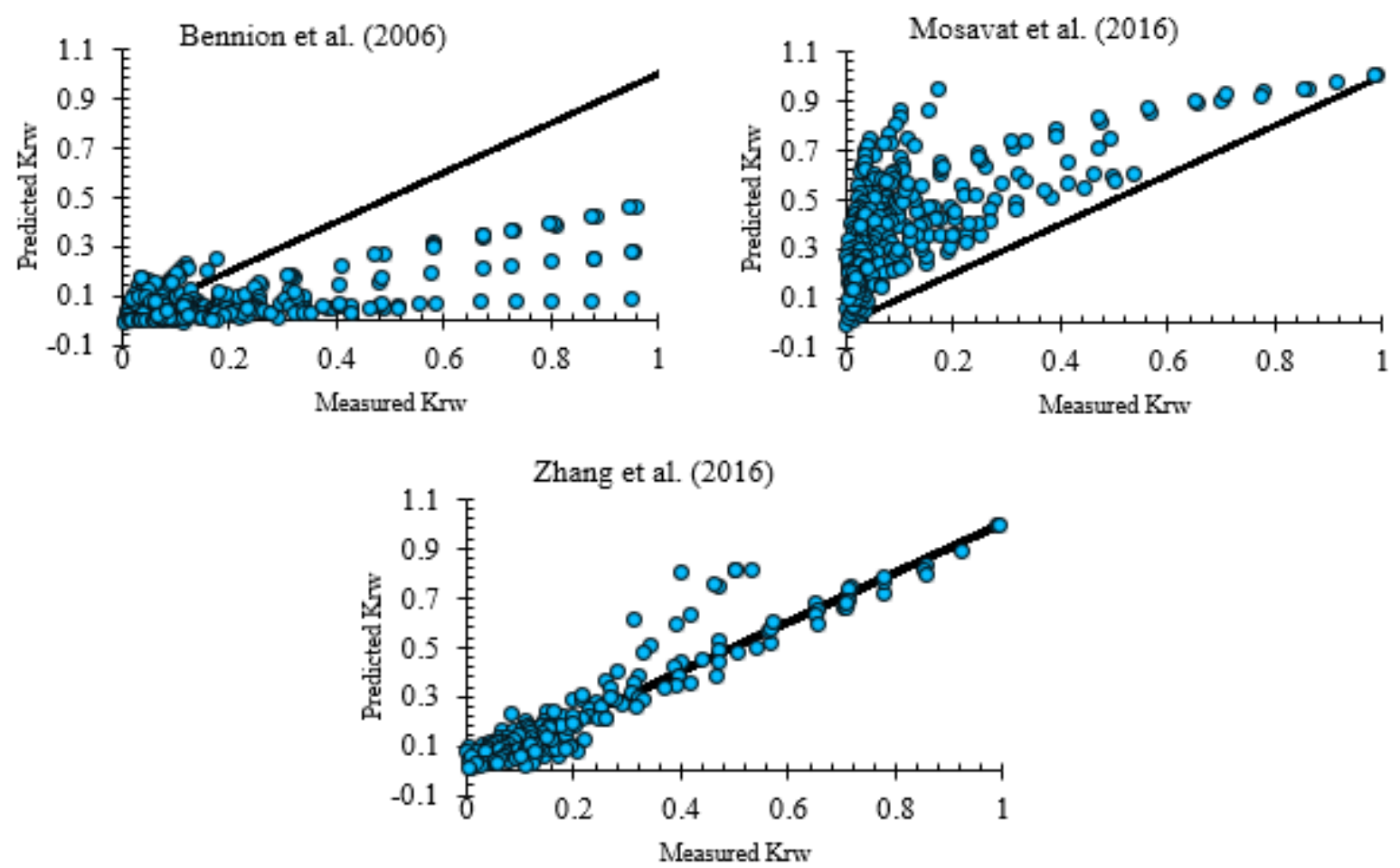

Fig. 13. Comparison of experimental and predicted temperature-based water relative permeability by Bennion et al., Mosavat et al. and Zhang et al. 

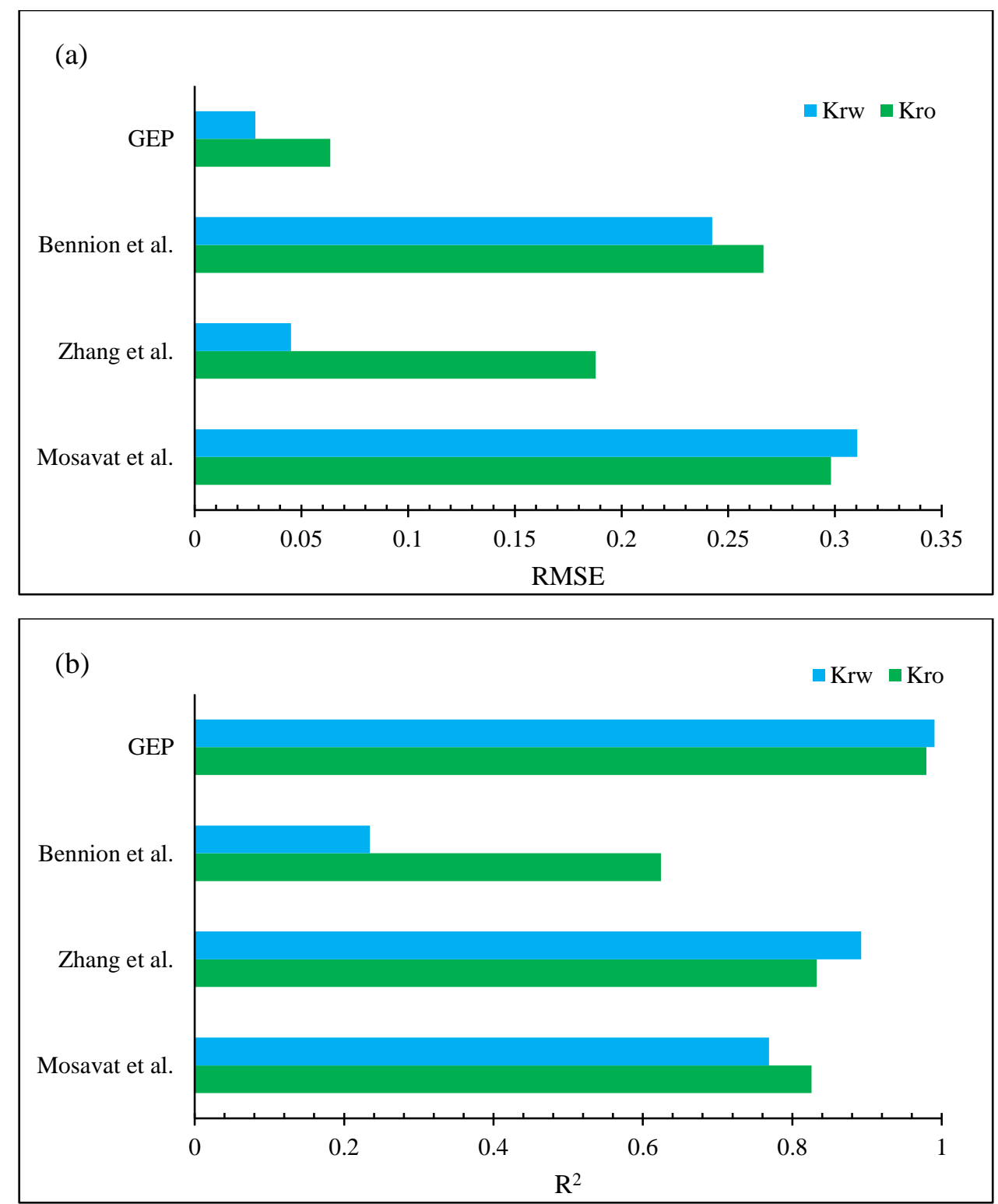

Fig. 14. The obtained (a) root mean squared error and (b) coefficient of correlation while estimating temperature-based oil/water relative permeability by GEP and available pre-existing correlations. 

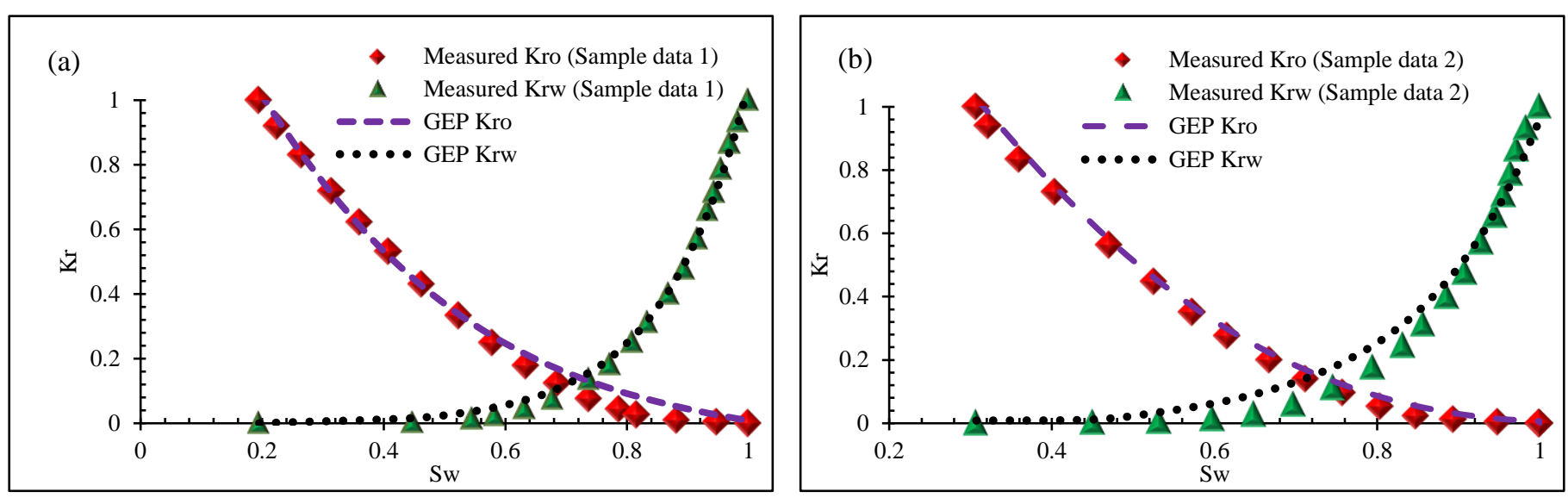

Fig. 15. Comparison between experimental values and outputs generated via GEP correlations versus water saturation for two cases included in this study. 